DOE Award number: DE-FG02-07ER86326

Recipient: Solexant Corp

Project title: Nanoparticle Solar Cell

Principle Investigator: Alison Breeze

Team members: Yudhisthira Sahoo, , Damoder Reddy, Veronica Sholin, Sue Carter

\title{
Nanoparticle Solar Cell Final Technical Report
}

\section{Executive Summary}

The purpose of this work was to demonstrate all-inorganic nanoparticle-based solar cells with photovoltaic performance extending into the near-IR region of the solar spectrum as a pathway towards improving power conversion efficiencies. The field of allinorganic nanoparticle-based solar cells is very new, with only one literature publication in the prior to our project. Very little is understood regarding how these devices function.

Inorganic solar cells with IR performance have previously been fabricated using traditional methods such as physical vapor deposition and sputtering, and solutionprocessed devices utilizing IR-absorbing organic polymers have been investigated. The solution-based deposition of nanoparticles offers the potential of a low-cost manufacturing process combined with the ability to tune the chemical synthesis and material properties to control the device properties.

This work, in collaboration with the Sue Carter research group at the University of California, Santa Cruz, has greatly expanded the knowledge base in this field, exploring multiple material systems and several key areas of device physics including temperature, bandgap and electrode device behavior dependence, material morphological behavior, and the role of buffer layers. One publication has been accepted to Solar Energy Materials and Solar Cells pending minor revision and another two papers are being written now.

While device performance in the near-IR did not reach the level anticipated at the beginning of this grant, we did observe one of the highest near-IR efficiencies for a nanoparticle-based solar cell device to date. We also identified several key parameters of importance for improving both near-IR performance and nanoparticle solar cells in general, and demonstrated multiple pathways which showed promise for future commercialization with further research.

\section{Overview}

The goal of this grant was to demonstrate all-inorganic nanoparticle-based solar cells with photovoltaic performance extending into the near-IR region of the solar spectrum as a pathway towards improving power conversion efficiencies. Inorganic solar cells with IR performance have previously been fabricated using traditional methods such as physical vapor deposition and sputtering, and solution-processed devices utilizing IRabsorbing organic polymers have been investigated elsewhere, but a solution-processed all-inorganic nanoparticle solar cell with IR performance had not yet been demonstrated. 
The solution-based deposition of nanoparticles offers a low-cost manufacturing method with the ability to tune the chemical synthesis and material properties to control the device properties.

The goal for this Phase I STTR grant was to demonstrate a power conversion efficiency of $\eta=1 \%$ in the wavelength region above $\lambda=750 \mathrm{~nm}$ in a nanoparticle-based allinorganic solar cell. While our results were not as high as initially anticipated, we did demonstrate some of the highest near-IR efficiencies for nanoparticle-based devices to date. We also learned a great deal about the functionality and material requirements for nanoparticle IR solar cells and demonstrated pathways towards potentially successful results with further research and development. We also greatly advanced knowledge and understanding in the newborn field of all-inorganic nanoparticle solar cells, which prior to this consisted of a single publication in the literature. Towards that end, one journal article co-authored with our collaborators at UC Santa Cruz has been submitted for publication in Solar Energy Materials and Solar Cells (SolMAT) and another two articles are in the process of being written.

The following report summarizes the material and device approaches used in this research and the knowledge and insight gained during the course of this grant. We investigated a wide variety of approaches for producing nanoparticle solar cells with performance in the near-IR above $\lambda=750 \mathrm{~nm}$, utilizing both bulk and quantum-confined properties of the IR-absorbing materials $\mathrm{PbSe}, \mathrm{HgTe}$ and $\mathrm{CdHgTe}$. An overview of the research approaches is summarized in Figure 1. We also studied CdTe nanoparticle devices to both further understanding of nanoparticle solar cell physics and as a framework for later application in CdHgTe near-IR devices.
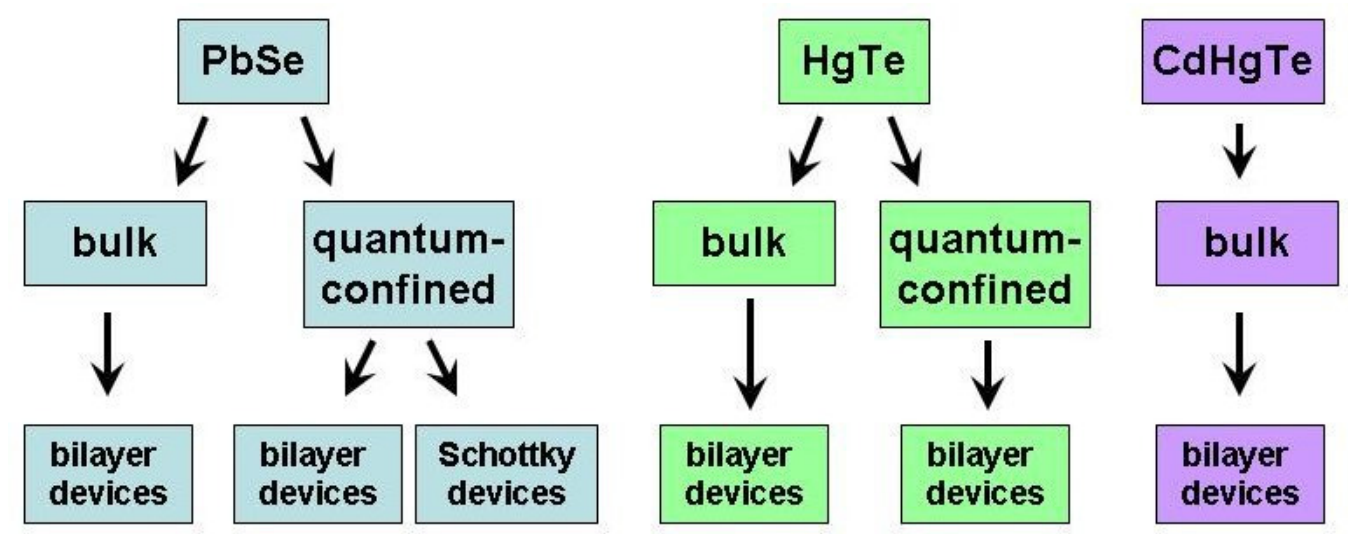

Figure 1: An overview of the materials and device approaches utilized over the course of the grant.

\section{Material Synthesis}

\section{PbSe nanoparticles}

$\mathrm{PbSe}$ nanoparticles were synthesized via a colloidal synthesis. In a typical reaction, $20 \mathrm{mmol}(4.4 \mathrm{~g})$ lead oxide $(\mathrm{PbO}), 20 \mathrm{ml}$ oleic acid, and $20 \mathrm{ml}$ trioctylamine are mixed in a three necked flask and heated under alternate vacuum and argon purge at $180 \mathrm{C}$ for 30-40 minutes. By this point, the reaction mixture turn has turned into a clear 
and colorless single phase solution. A needle is then inserted through the septum to let moisture and vapor-phase side products escape. The needle is removed after about 30 min and the temperature is brought down to $155 \mathrm{C}$.

Meanwhile, $3.2 \mathrm{~g} \mathrm{Se}$ is dissolved in $20 \mathrm{ml}$ tributylphosphine (TBP-Se, 2M) inside the glove box and loaded into a syringe. $400 \mu 1$ diphenylphosphine (DPP) is loaded into another syringe. These syringes are brought outside the glovebox and the contents of both are injected into the reaction pot simultaneously. The size of the particles is determined by the reaction time; for this work, a typical reaction time of 110-120 seconds was used to produce particles of $\sim 4 \mathrm{~nm}$ corresponding to a highest excitonic peak of $\sim 1500 \mathrm{~nm}$. Shorter reaction times, down to 10-20 seconds, can be used to produce smaller particles. Heating is ceased by lowering the heating mantle and the reaction is stopped by quickly cooling the flask either by injecting $\sim 50 \mathrm{ml}$ trioctylamine or by bringing a chilled bath underneath the flask.

The product mixture is transferred by a cannula to an argon filled bottle and transferred into the glove box. Dry ethanol $(\sim 150-200 \mathrm{ml})$ is added to the mixture, which is first vortexed for 5-7 minutes and then centrifuged at $3200 \mathrm{rpm}$ for ten minutes. The supernatant is clear and is discarded. The precipitate is redissolved in $50 \mathrm{ml}$ toluene and mixed with $150 \mathrm{ml}$ ethanol for a second centrifugation of ten minutes. The second precipitate is dissolved in $8-10 \mathrm{ml}$ chloroform and filtered through a $0.2 \mu \mathrm{m}$ membrane filter to remove any large particle aggregates.

The PbSe particles were characterized by solution absorption (Figure 2A), TEM (Figure 2B) and thermogravimetric analysis (TGA).
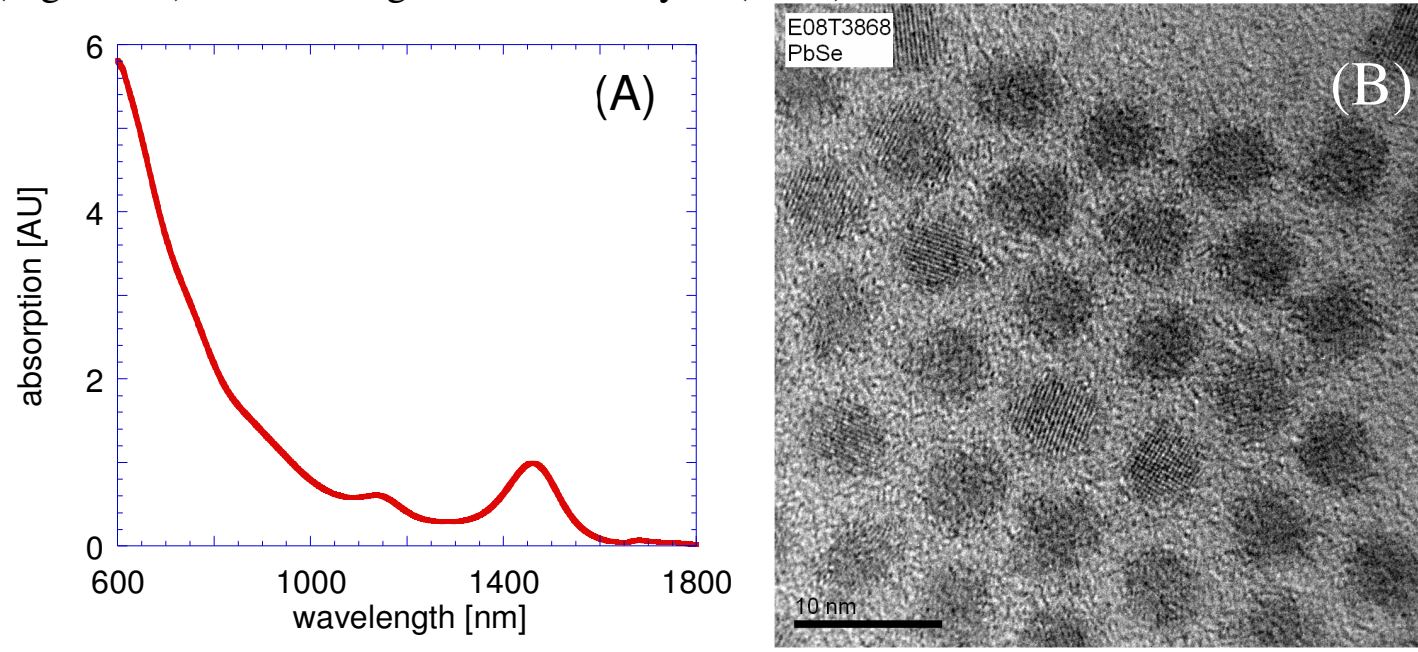

Figure 2: (A) PbSe solution absorption spectra; (B) a TEM image of the PbSe particles used in the quantum-confined device work described below.

\section{$\mathrm{Cd}_{\mathrm{x}} \mathrm{Hg}_{1-\mathrm{x}} \mathrm{Te}$ nanoparticles}

$\mathrm{Cd}_{\mathrm{x}} \mathrm{Hg}_{1-\mathrm{x}} \mathrm{Te}$ nanoparticles are synthesized in an aqueous solution and subsequently transferred to an organic phase. In a typical reaction for $\mathrm{Cd}_{\mathrm{x}} \mathrm{Hg}_{1-\mathrm{x}} \mathrm{Te}$ with a target of $\mathrm{x}=60 \%(40 \% \mathrm{Hg}), 3.11 \mathrm{~g}$ cadmium perchlorate $\left(\mathrm{Cd}\left(\mathrm{ClO}_{4}\right)_{2} \mathrm{x} \mathrm{H}_{2} \mathrm{O}, \mathrm{FW}=311.11\right)$, $2 \mathrm{ml}$ thioglycerol and enough $\mathrm{NaOH}$ to maintain the $\mathrm{pH}$ at 11-12 are dissolved in $500 \mathrm{ml}$ water in a flask and deaerated for $\sim 15$ mins on an ice bath (Flask 1). In a separate flask, 
$1.6 \mathrm{~g}$ mercury perchlorate $\left(\mathrm{Hg}\left(\mathrm{ClO}_{4}\right)_{2} \times \mathrm{H}_{2} \mathrm{O}, \mathrm{FW}=399.49\right), 50 \mathrm{ml}$ water, $1 \mathrm{ml}$ thioglycerol and enough $\mathrm{NaOH}$ to maintain $\mathrm{pH}$ at 11-12 are mixed (Flask 2).

In a $40 \mathrm{ml}$ vial, $2 \mathrm{~g}$ aluminum telluride is placed and sealed by a septum fitted with a hard rubber pipe to pass $\mathrm{H}_{2} \mathrm{Te}$ gas. The other end of the pipe is immersed in the Flask $1.1 \mathrm{ml} \mathrm{H}_{2} \mathrm{SO}_{4}$ is diluted to $5 \mathrm{ml}$ and loaded into a syringe. The acid is dropped into the aluminum telluride while keeping the vial in ice bath. The resulting product, $\mathrm{H}_{2} \mathrm{Te}$ gas, is bubbled into Flask 1 and orange coloration appears indicating the formation of CdTe dots.

In later experiments, we explored the use of the Te precursor NaHTe in place of $\mathrm{H}_{2}$ Te gas. $0.64 \mathrm{~g}(0.5 \mathrm{mmole})$ tellurium powder is weighed inside the glove box and placed in a closed vial fitted with a septum before being brought outside of the glovebox. $20 \mathrm{ml}$ water and 12 mmole sodium borohydride are added and Ar flushed continuously for two hours. By this point, all the tellurium powder has dissolved and the color of the solution is light pink. This product is NaHTe $(0.5$ mmole in $20 \mathrm{ml})$ and can be stoichiometrically used for the preparation of either $\mathrm{Cd}_{\mathrm{x}} \mathrm{Hg}_{1-\mathrm{x}} \mathrm{Te}$ or $\mathrm{HgTe}$.

Following this the content of Flask 2 is slowly poured into Flask 1 . The solution color instantly turns dark, indicating the binding of $\mathrm{Hg}$ ions to the $\mathrm{CdTe}$ particles. The resulting product $\left(\mathrm{Cd}_{\mathrm{x}} \mathrm{Hg}_{1-\mathrm{x}} \mathrm{Te}\right)$ is precipitated from the aqueous dispersion by adding excess acetone ( aqueous: acetone ratio 1:5) and centrifuging. The $\mathrm{Cd}_{\mathrm{x}} \mathrm{Hg}_{1-\mathrm{x}} \mathrm{Te}$ particles are easily re-dispersed in water $(\sim 20 \mathrm{ml})$.

In order to transfer the particles from aqueous to organic solution, $20 \mathrm{ml} \mathrm{Cd}_{\mathrm{x}} \mathrm{Hg}_{1}$ ${ }_{x}$ Te solution is mixed with $20 \mathrm{ml}$ dodecanethiol (DDT) and $60 \mathrm{ml}$ acetone. This mixture is heated at 70C for 1-2 hours, during which time the particles transfer to the organic DDT layer. The particles are precipitated from the organic layer by adding acetone and redispersed in chloroform for two cycles. The final solution is passed through a $0.2 \mu \mathrm{m}$ membrane filter.

The $\mathrm{Cd}_{\mathrm{x}} \mathrm{Hg}_{1-\mathrm{x}}$ Te particles were characterized by absorption spectra (Figure 3 ), energy dispersive spectroscopy (EDS) and direct coupled plasma (DCP), the latter two measurements used to determine the degree of $\mathrm{Hg}$ incorporation. Feedback from these measurements, showing a higher $\mathrm{Hg}$ inclusion than anticipated, guided later synthesis batches to tune the $\mathrm{Hg}$ content.

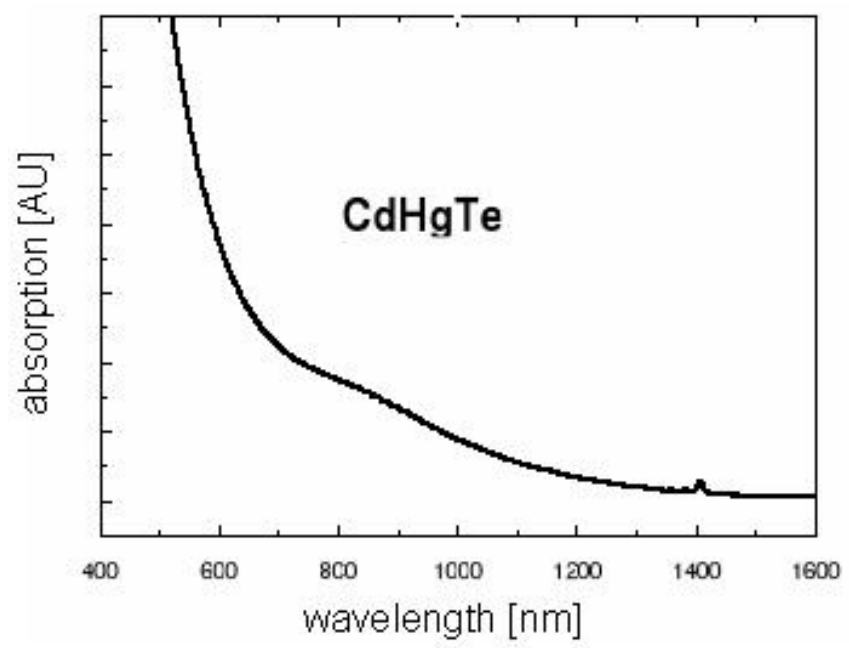

Figure 3: Solution absorption spectra for one example of $\mathrm{CdHgTe}$ nanoparticles. 


\section{HgTe nanoparticles}

$\mathrm{HgTe}$ particles are prepared by passing $\mathrm{H}_{2} \mathrm{Te}$ gas into a mercuric perchlorate only solution (no cadmium perchlorate) in conditions otherwise identical to the preparation of described above for $\mathrm{Cd}_{\mathrm{x}} \mathrm{Hg}_{1-\mathrm{x}} \mathrm{Te}$. The phase transfer is achieved by the same procedure as described above.

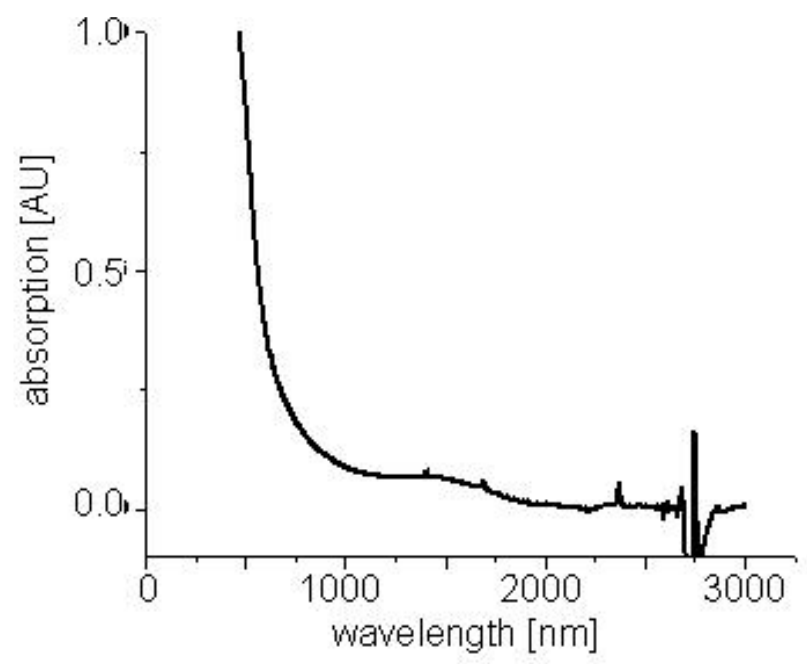

Figure 4: HgTe nanoparticle solution absorption spectrum.

\section{CdTe nanorods}

In a typical reaction, $4 \mathrm{~g}$ cadmium oxide $(\mathrm{CdO}), 16.2 \mathrm{~g}$ octadecylphosphonic acid (ODPA), 6.2 g octyl phosphonic acid (OPA) and $53 \mathrm{~g}$ trioctylphosphonic oxide (TOPO, 99\%) are loaded in a three necked flask and heated under alternate vacuum and argon purge for an hour at a set temperature of $320 \mathrm{C}$, by which point the reaction mixture has formed a homogeneous clear solution. $30 \mathrm{ml}$ trioctylphosphine (TOP, 98\%) is introduced to the mixture and the heating continued for an additional 30 minutes. Next, $24 \mathrm{ml} 1 \mathrm{M}$ TOP-Te (tellurium dissolved in TOP at a concentration of $1 \mathrm{M}$ ) is rapidly injected, resulting in a brown solution indicative of the formation of CdTe nanorods (NRs). The reaction is stopped after 4 minutes by withdrawing the heating mantle. After the flask has cooled to a temperature of $80-100 \mathrm{C}, \sim 50 \mathrm{ml}$ toluene is mixed with the product and the entire content of the flask is taken inside the glove box where it is mixed with 2-propanol (until slight cloudiness appears) and transferred into centrifuge tubes for precipitation and redispersion cycles.

For sintered device fabrication, it is advantageous to utilize ligands which can be removed by thermal annealing at moderate rather than high temperatures. For this reason, the CdTe NRs are surface exchanged with the more easily removable ligand pyridine. For simplicity, pyridine is used as the solvent as well. For this, the final precipitate from above (i.e. after centrifugation with 2-propanol) is transferred to a 3-neck flask and 700 
$\mathrm{ml}$ pyridine added. The NR suspension in pyridine is subjected to 20-24 hour refluxing under argon after which it forms a clear dispersion in pyridine. The phosphonic acid ligands replaced by pyridine are still in the solvent, and need to be removed. This is done by precipitating the NRs from the pyridine dispersion by adding excess hexane and redissolving the precipitate in pyridine. A final concentration of $60-70 \mathrm{mg} / \mathrm{ml}$ is used to produce high quality uniform films.

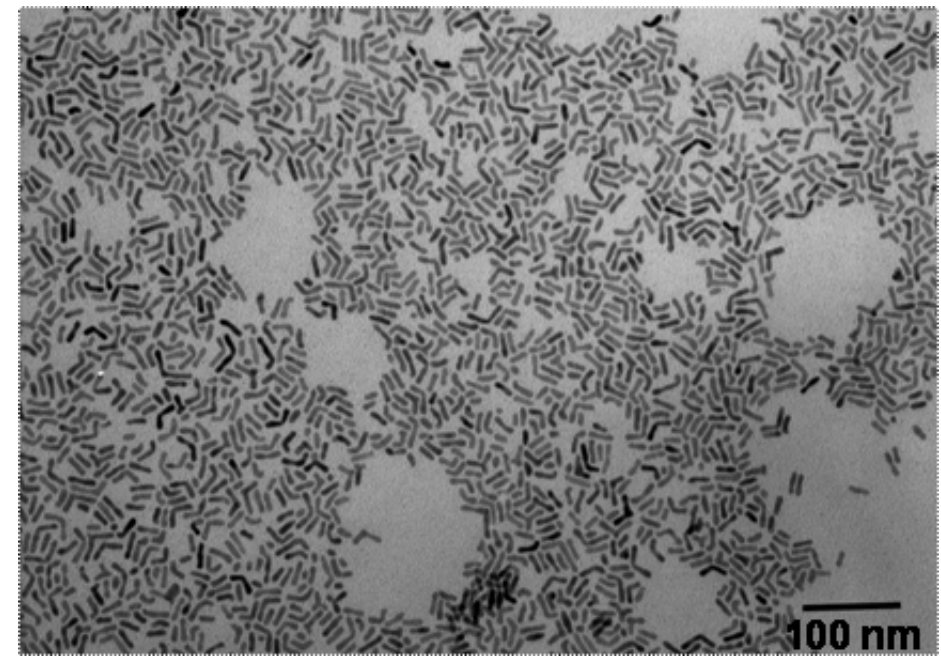

Figure 5: TEM image of CdTe nanorods.

\section{CdSe nanorods}

The preparation of CdSe NRs is very similar to the above description for CdTe. In a routine synthesis, $4.10 \mathrm{~g} \mathrm{CdO}, 14.2 \mathrm{~g}$ tetradecylphosphonic acid (TDPA), $3.20 \mathrm{~g}$ hexylphosphonic acid (HPA) and $60 \mathrm{~g}$ TOPO are heated together to a temperature of $300 \mathrm{C}$ under the aforementioned conditions. $30 \mathrm{ml}$ TOP is added and the heating continued for 30 minutes more. $10 \mathrm{ml} \mathrm{1M} \mathrm{TOP-Se} \mathrm{(selenium} \mathrm{dissolved} \mathrm{in} \mathrm{TOP)} \mathrm{is} \mathrm{rapidly}$ injected producing NRs of CdSe. The precipitation-redispersion cycle and the final pyridine dispersion are identical to the one described for CdTe NRs. 


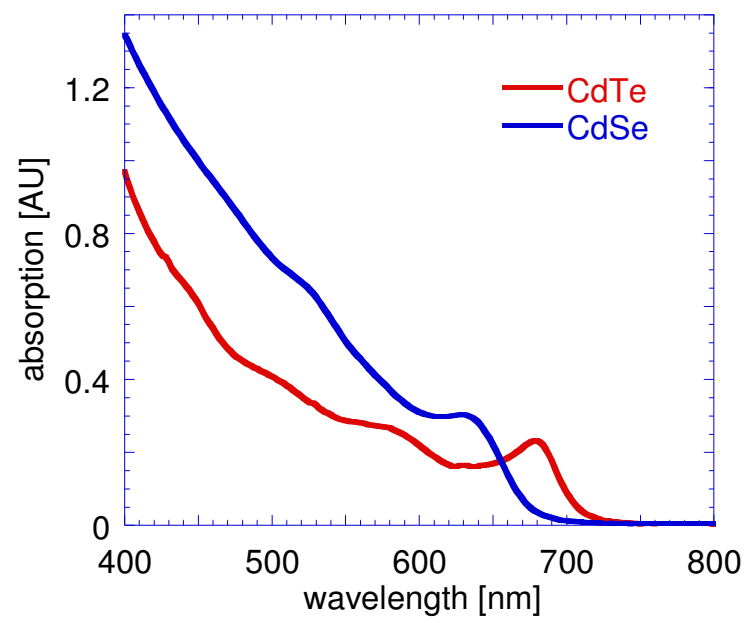

Figure 6: CdTe and CdSe nanorod solution absorption spectra.

\section{CdSe nanoparticles}

CdSe nanoparticles, rather than CdSe NRs, were used for some of the early work for this grant. In a routine synthesis, $3.45 \mathrm{~g}$ cadmium carbonate $\left(\mathrm{CdCO}_{3}\right), 14.12 \mathrm{~g}$ oleic acid and $75 \mathrm{ml}$ trioctylamine are taken in a three necked flask. Under alternate argon and vacuum, the flask is heated at $280 \mathrm{C}$ for 30 minutes. The heating is continued for another 30 minutes under argon with a needle pierced through the septum to let vaporized side products escape. $10 \mathrm{ml} 1 \mathrm{M}$ TBP-Se (selenium dissolved in tributylphosphine) is rapidly injected by a syringe and the heating continued for an additional 30 minutes. The CdSe QDs formed are retrieved by the established washing procedure discussed earlier for NRs. The QDs are dispersed in chloroform or dichlorobenzene.

\section{Device Fabrication and Results}

\section{PbSe sintered nanoparticle solar cells}

We initially studied $\mathrm{PbSe}$ solar cells as an attempt to improve absorption and quantum efficiency in the IR portion of the solar spectrum. Our strategy was to replace the CdTe p-type layer with a PbSe p-type layer, following a similar device structure originally proposed by Gur et al. For these $\mathrm{CdSe} / \mathrm{PbSe}$ devices, we found that an additional buffer layer, such as $\mathrm{LiF}$ or $\mathrm{Al}_{2} \mathrm{O}_{3}$, was needed to obtain reproducible solar cell performance. We fabricated unoptimized solar cells with a short-circuit current of $6 \mathrm{~mA} / \mathrm{cm}^{2}$, an opencircuit voltage of $0.18 \mathrm{~V}$, and a fill factor of $41 \%$. The PbSe in these devices did not contribute to the quantum efficiency even though it was a necessary component to make a working solar cell. We concluded the solar cell did not behave as either a typical p-n or type-II heterojunction donor/acceptor. A paper on these results was submitted to Solar Energy Materials and Solar Cells and has now been accepted for publication pending minor revisions. 
The $\mathrm{CdSe} / \mathrm{PbSe}$ devices were fabricated on ITO-patterned glass by Thin Film Devices (Anaheim, CA) which were cleaned by successively introducing the substrates into a sonic bath in an Alconox/deionized water solution, ethanol, and finally acetone, and then dried with a nitrogen gun. CdSe nanoparticle solution was spin-cast at $1000 \mathrm{rpm}$ and then sintered at $400^{\circ} \mathrm{C}$ for $10 \mathrm{~min}$ in air. CdSe film thickness ranged from $240 \mathrm{~nm}$ to $550 \mathrm{~nm}$, depending on the concentration of the nanoparticle solution. A film of LiF was then thermally evaporated on the CdSe layer, and this was followed by a film of $\mathrm{PbSe}$ nanoparticles, also spun at $1000 \mathrm{rpm}$ and sintered at $400^{\circ} \mathrm{C}$ for $10 \mathrm{~min}$ in air. PbSe film thickness ranged from $90 \mathrm{~nm}$ to $340 \mathrm{~nm}$. The nanoparticle films were sintered by introducing the substrates in a tube furnace at setpoint temperature; this was required to obtain short circuit currents above $0.1 \mathrm{~mA} / \mathrm{cm}^{2}$. Finally, $\mathrm{Al}$ or Au were thermally evaporated as the top metal electrode. Interlayers of $\mathrm{Al}_{2} \mathrm{O}_{3}$ were obtained by thermally evaporating a thin $\mathrm{Al}$ film over the $\mathrm{CdSe}$ layer, and then sintering at $400^{\circ} \mathrm{C}$ for $2 \mathrm{~min}$ in air.

Figure 7a shows the IV characteristics for a typical $\mathrm{ITO} / \mathrm{CdSe} / \mathrm{PbSe} / \mathrm{Al}$ device and an $\mathrm{ITO} / \mathrm{CdSe} / \mathrm{LiF}(34 \mathrm{~nm}) / \mathrm{PbSe} / \mathrm{Al}$ device. The device without an interlayer shows severe shunting, high dark current, and no photovoltage or photocurrent.

Incorporating an interlayer into the structure lowers the dark current and produces a photocurrent and a photovoltage under illumination. The dependence of device performance on $\mathrm{LiF}$ interlayer thickness is shown in Fig. $7 \mathrm{~b}$. The variability in nanoparticle solution and subsequent film quality led to variable optimal LiF film thickness; a trend was observed, however, whereby devices showed enhanced performance for thicknesses up to around $45 \mathrm{~nm}$ and performance decline starting around $50 \mathrm{~nm}$. We have observed that in general thicker nanoparticle films (up to $500 \mathrm{~nm}$ for CdSe films) resulted in higher performance devices. The IV characteristics of devices with optimized $\mathrm{LiF}$ thickness were: $\mathrm{J}_{\mathrm{sc}}$ of $6 \mathrm{~mA} / \mathrm{cm}^{2}, \mathrm{~V}_{\mathrm{oc}}$ of $0.18 \mathrm{~V}$, and $\mathrm{FF}$ of $41 \%$. The shunt resistance of ITO/CdSe/LiF/PbSe/Al devices monotonically increased with $\mathrm{LiF}$ layer thickness. This was consistent with the observation that introduction of an interlayer generally lowered the dark
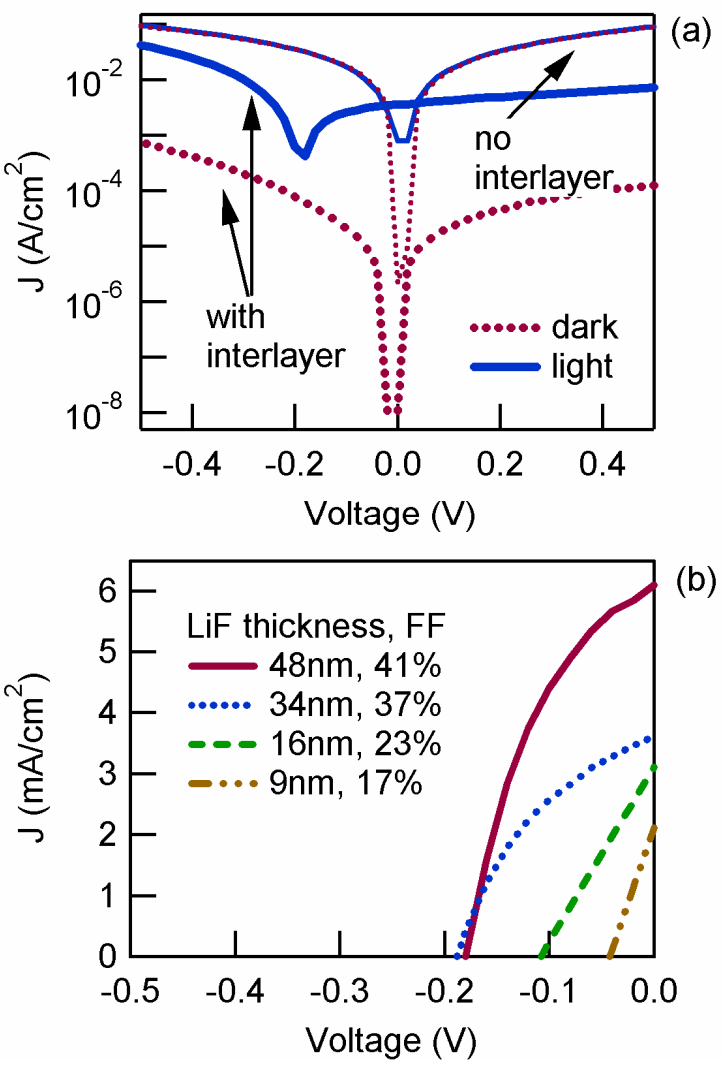

Figure 7: (a) Comparison of device performance in the dark (thin lines) and under AM1.5D illumination (thick lines) of $\mathrm{ITO} / \mathrm{CdSe} /(\mathrm{LiF}) / \mathrm{PbSe} / \mathrm{Al}$ devices, with and without a $\mathrm{LiF}$ interlayer. (b) Dependence of device performance on LiF interlayer thickness. 
current of the devices.

To further understand the function of the interlayer, we replaced $\mathrm{LiF}$ with $\mathrm{Al}_{2} \mathrm{O}_{3}$ (Figure 8). These devices showed similar behavior to the $\mathrm{LiF}$ interlayer counterparts, although $20 \mathrm{~nm}$ of $\mathrm{Al}_{2} \mathrm{O}_{3}$ were sufficient to achieve IV characteristics similar to those of a device with a $50 \mathrm{~nm} \mathrm{LiF}$ interlayer. We attribute the difference in thicknesses to the small but non-negligible conductivity of the $\mathrm{LiF}$ layer. By thermally evaporating a $\mathrm{LiF}$ film and an Al electrode on an ITO substrate and then measuring the IV curve of the structure, we verified that the LiF films

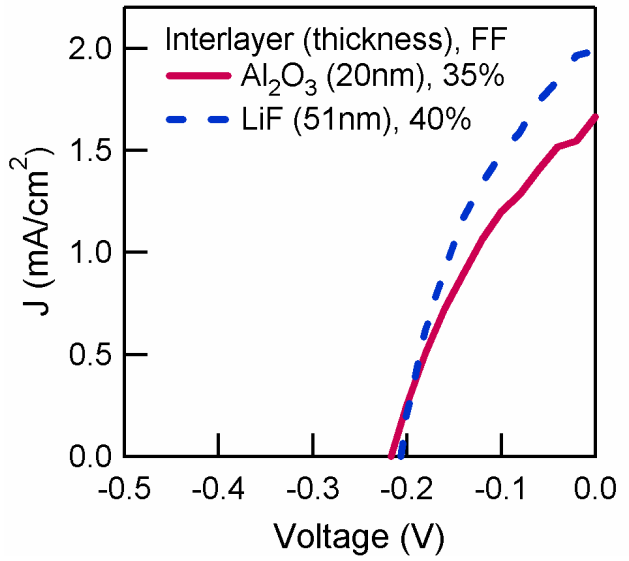

Figure 8: Comparison of $\mathrm{Al}_{2} \mathrm{O}_{3}(20 \mathrm{~nm})$ and $\mathrm{LiF}(50 \mathrm{~nm})$ interlayer devices. exhibited a conductivity of $10^{-7} \mathrm{~S} / \mathrm{cm}$. We also tested the effect of introducing a thick, $30 \mathrm{~nm} \mathrm{LiF}$ interlayer into a poly[2,5dimethoxy-1,4-phenylene-1,2-ethenylene-2-methoxy-5-(2-ethylhexyloxy)-1,4-phenylene1,2-ethenylene]/poly[oxa-1,4-phenylene-1,2-(1-cyano)-ethenylene-2,5-dioctyloxy-1,4phenylene-1,2-(2-cyano)-ethenylene-1,4-phenylene] (M3EH-PPV/CN-ether-PPV) polymer bilayer system, which has been well studied by our group in the past [29].

Devices prepared with a $30 \mathrm{~nm}$ thick LiF interlayer resulted in a $\mathrm{J}_{\mathrm{sc}}$ of less than $1 \mu \mathrm{A} / \mathrm{cm}^{2}$, over a two order of magnitude decrease, as well as a greatly reduced $\mathrm{V}_{\text {oc }}$ of less than $0.05 \mathrm{~V}$. For the polymer devices, the LiF layer acts as an impediment to charge transfer and transport.

AFM images (Figure 9) showed that the $\mathrm{CdSe}$ films had a root-mean-square roughness ( $\mathrm{R}_{\mathrm{rms}}$ ) of less than $5 \mathrm{~nm}$ and the PbSe films presented an $R_{\text {rms }}$ of up to $16 \mathrm{~nm}$. In general we were not able to resolve any aggregates in the CdSe AFM images, while sintered PbSe nanoparticle aggregates exhibited diameters of the order of $0.50-0.75 \mu \mathrm{m}$. Inspection of the as-cast films revealed that the extent of aggregation and the size of the aggregates in the sintered film depended more heavily on aggregation in the nanoparticle solutions than on the sintering process. The CdSe films that resulted in the best devices had an $R_{\mathrm{rms}}$ of around $2 \mathrm{~nm}$, and in general we observed that obtaining very smooth nanoparticle films was crucial to fabricate the highest efficiency solar cells. We also observed that, in general, thicker nanoparticle films (up to $500 \mathrm{~nm}$ for CdSe films) resulted in higher performance
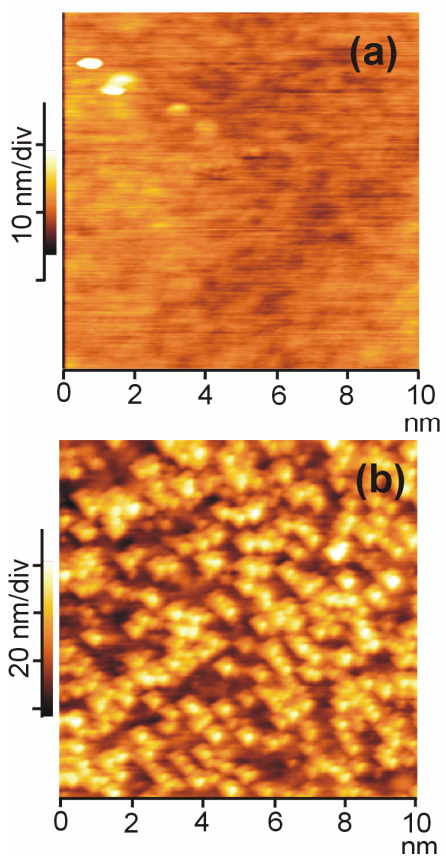

Figure 9: AFM of (a) CdSe and (b) PbSe nanoparticle films. Note the difference in vertical scales. 
devices. The films appeared to be pinhole-free; however, smaller pinholes may have remained undetected because of the horizontal resolution of the AFM.

In Figure 10, the absorption spectra of an as-cast $\mathrm{CdSe}$ film, a sintered CdSe film, and a sintered PbSe film, as well as the external quantum efficiency (EQE) of a typical ITO/CdSe/LiF/PbSe/Al device, are shown. Using the cutoff wavelength of the CdSe absorption spectra, we can calculate a rough estimate of the bandgap of the nanoparticle film ascast and after sintering. Nanoparticles of different sizes were used to fabricate devices. For the CdSe particles whose absorption spectra are

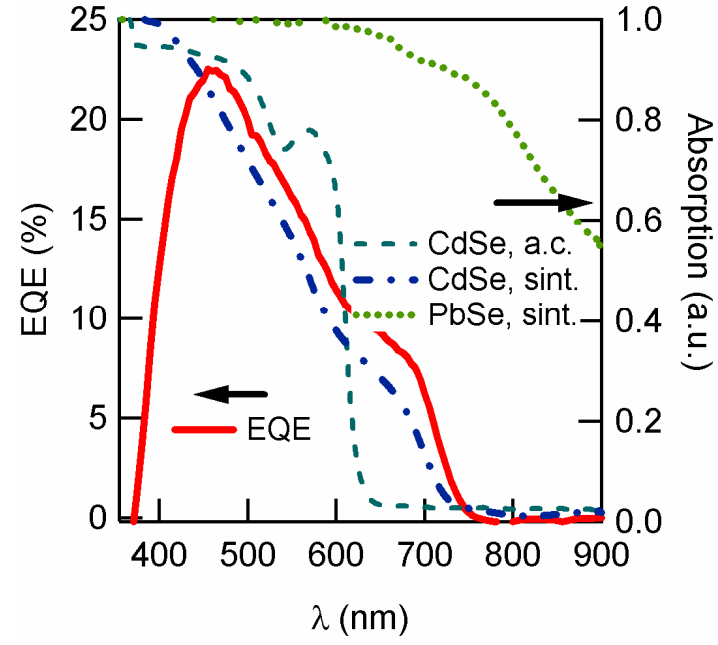

Figure 10: EQE of ITO/CdSe/LiF/PbSe/Al solar cells vs. the absorption of an as-cast (a.c.) CdSe film, a sintered (sint.) CdSe film, and a sintered $\mathrm{PbSe}$ film. displayed in Fig. 6 in particular, we calculate an as-cast bandgap of around $1.97 \mathrm{eV}$ (630 $\mathrm{nm}$ absorption cutoff) and a sintered bandgap of around $1.70 \mathrm{eV}$ (730 nm absorption cutoff).

Further inspection of Figure 10 shows that the cutoff of the EQE spectrum coincides with the cutoff of the sintered CdSe film and that few photons with wavelengths above $750 \mathrm{~nm}$, if any, are collected as charge at the electrodes. Because the highest excitonic peak of the PbSe nanoparticles was around $1200 \mathrm{~nm}$, we expected that these solar cells would collect a portion of the infrared range of the solar spectrum. Although the EQE data may seem to suggest that the PbSe film does not play a role in these devices, other tests demonstrate the opposite. We fabricated $\mathrm{ITO} / \mathrm{CdSe} / \mathrm{LiF} / \mathrm{Al}$ and ITO/CdSe/LiF/CdSe/Al devices, neither of which showed a photovoltaic effect. This suggests that the $\mathrm{PbSe}$ film is a necessary component of the system. Inspection of the current polarity showed that holes exited through the ITO and electrons exited through the top electrode. We inverted the order of the nanoparticle layers to test the ITO/PbSe/interlayer/CdSe/Al structure, with and without an interlayer. The devices showed severe shunting and no photovoltaic response, as is usually the case for $\mathrm{CdSe} / \mathrm{PbSe}$ devices that do not have an interlayer. In ITO/CdSe/interlayer/PbSe/Al devices we substituted the top $\mathrm{Al}$ electrode with $\mathrm{Au}$, and observed somewhat lower $\mathrm{J}_{\mathrm{sc}} \mathrm{S}$ and FFs, but similar $\mathrm{V}_{\mathrm{oc}}$.

The data indicates that the main purpose of the interlayer is to interrupt shunting pathways traversing one or both nanoparticle films. This could take place by shielding the underlying CdSe layer from direct contact with the top Al electrode or by increasing the resistance of the shunted pathways in the $\mathrm{PbSe}$ films, which could exist along $\mathrm{Pb}$-rich grain boundaries or along other inhomogeneities in the film. In one instance alone we were able to fabricate an ITO/CdSe/PbSe/Al device with no interlayer, which yielded a $\mathrm{J}_{\mathrm{sc}}$ of $1.1 \mathrm{~mA} / \mathrm{cm}^{2}, \mathrm{~V}_{\mathrm{oc}}$ of $0.11 \mathrm{~V}$, and a FF of $25 \%$. This suggests that from an energy level point of view it is possible to obtain a photovoltaic effect from these devices 
without the use of an interlayer; nevertheless, reproducibility was highly affected by film quality. Placed either between the nanoparticle films or above the nanoparticle bilayer, the LiF film may be further reducing leakage by passivating the nanoparticle surfaces and reducing the number of interfacial traps and recombination centers.

Finally, we consider the operational mechanism for these solar cell devices. The EQE of an ITO/CdSe/LiF/PbSe/Al device, shown in Figure 10, demonstrates that the solar cells are collecting a negligible amount of charges at photons of wavelengths above 750 $\mathrm{nm}$, where the $\mathrm{PbSe}$ is expected to contribute. The PbSe nanoparticle films are known to be photoconductive, indicating that the $\mathrm{PbSe}$ does not contribute because it is energetically unfavorable for it to transfer charge to the CdSe layer. Study of the polarity of the current through these devices revealed that, strikingly, holes are collected through the ITO and electrons are collected through the top electrode.

Figure 11 shows the energy band diagram of the structure in which any possible energy level shifts due to the interlayer or to the sintering of the nanoparticle films are ignored. Although the literature provides examples in which the PbSe film is the electron transporter, the scheme in Figure 11a suggests that electrons should exit through the $\mathrm{CdSe}$ film. Figure $11 \mathrm{~b}$ illustrates a possible energy diagram of the structure accounting for a decrease in the energy bandgap of the nanoparticle films once sintered. As observed by in Figure 10, the bandgap approach the bulk value when the nanoparticles are sintered at $400^{\circ} \mathrm{C}$. Since the bandgap of bulk CdSe has a value of around $1.7 \mathrm{eV}$ and the average bandgap of CdSe nanoparticles is around $2.0 \mathrm{eV}$, the change in film bandgap after sintering will have relatively minor consequences on the energy band diagram of the structure. However, an analogous change in the $\mathrm{PbSe}$ film could have significant consequences on the device energetics. Because PbSe has a large Bohr radius (46 nm compared to only $6 \mathrm{~nm}$ for $\mathrm{CdSe}$ ) and thus shows strong quantum confinement, the difference in bandgap between bulk and nanoparticle bandgap for PbSe is large $(0.27 \mathrm{eV}$ vs. $\sim 1.0 \mathrm{eV}$ ). As shown in Figure $11 \mathrm{~b}$ this would cause the lowest unoccupied molecular orbital (LUMO) of the PbSe film to shift farther from vacuum and reach a value close to that of the LUMO of CdSe. To reconcile the polarity of the current with the energy levels in Figure 11b, we suggest that while electrons could travel in either the CdSe or PbSe films because of the similarity in the LUMO energies of the materials, holes may not be transferred from the PbSe to the CdSe because it is energetically unfavorable to do so. In this case, electron-hole pairs generated upon photon absorption in the PbSe film would not be collected since hole transfer to the CdSe would not occur, and thus the electronhole pairs would ultimately recombine. Further support for this model is the observation that devices consisting of non-sintered PbSe layers did not exhibit solar cell performance. 
Gur et al. showed that their all-inorganic nanoparticle CdTe/CdSe system behaved like a donor/acceptor type-II heterojunction. Our experiments and the literature suggest that this might not be the case for our system. The energy band diagram for our system does not present a clear scheme of staggered energy levels, so that it is not clear that we have a type-II heterojunction. Also, because the conductivity of the $\mathrm{PbSe}$ layer is a few orders of magnitude higher than the conductivity of the $\mathrm{CdSe}$, and because we have found that the PbSe is necessary in order to collect the charge photogenerated in the CdSe, yet it does not contribute itself to the photocurrent observed, we believe this system does not behave like a typical donor-acceptor system. Instead, this system might be more similar to a $\mathrm{TiO}_{2} /$ conjugated polymer system in which the CdSe is the photoactive material and the $\mathrm{PbSe}$ acts as a low resistivity electron accepting contact.

Finally, we considered whether the ITO/CdSe/(interlayer)/ $\mathrm{PbSe} / \mathrm{Al}$ could be behaving like a p-n junction system. Because CdSe is an ntype material, electron transport by the PbSe film would have had to stem from an even stronger ntype doping of the PbSe. The literature on PbSe thin films indicates that photoconductivity in this material, which we observed and presented in Fig. 5 , is possible when oxygen impurities introduce acceptor levels into the energy band of PbSe, making it p-type. While it may not be entirely correct to apply literature on semiconductor thin films, which is mostly based on mono- or polycrystalline systems, to nanoparticle solids, we found the data in the literature to be irreconcilable with our observations of the photoconductivity and electron conduction in $\mathrm{PbSe}$.

\section{$\mathrm{Cd}_{\mathrm{x}} \mathrm{Hg}_{1-\mathrm{x}} \mathrm{Te}$ nanoparticle solar cells}

When $\mathrm{Hg}$ is doped into CdTe to form the ternary compound $\mathrm{Cd}_{\mathrm{x}} \mathrm{Hg}_{1-\mathrm{x}} \mathrm{Te}$, the absorption spectrum is shifted past the CdTe absorption edge of $850 \mathrm{~nm}$ and into the nearIR. The amount of incorporated $\mathrm{Hg}$ determines the energy level shift, allowing one to tune the bandgap by controlling the doping level. With a tunable band-gap going into the near-IR, CdHgTe allows one to construct a bulk-material-based solar cell with performance in our target range of $\lambda>750 \mathrm{~nm}$. Literature reports have demonstrated that $\mathrm{Cd}_{\mathrm{x}} \mathrm{Hg}_{1-\mathrm{x}} \mathrm{Te}$ can be used in place of $\mathrm{CdTe}$ in a $\mathrm{CdS} / \mathrm{CdTe}$ heterojunction device, with many of the known CdTe device processing steps being applicable for the $\mathrm{Cd}_{\mathrm{x}} \mathrm{Hg}_{1-\mathrm{x}} \mathrm{Te}$ device. 
For these reasons, we investigated the synthesis of $\mathrm{Cd}_{\mathrm{x}} \mathrm{Hg}_{1-\mathrm{x}} \mathrm{Te}$ nanoparticles to be incorporated into $\mathrm{Cd}_{\mathrm{x}} \mathrm{Hg}_{1-\mathrm{x}} \mathrm{Te} / \mathrm{CdSe}$ sintered devices, a design analogous to a CdTe / $\mathrm{CdSe}$ solar cell presented in the literature and further explored by our group.

For initial trials, devices with the structure $\mathrm{Cd}_{\mathrm{x}} \mathrm{Hg}_{1-\mathrm{x}} \mathrm{Te} / \mathrm{CdSe}$ were fabricated under low processing temperatures of $220 \mathrm{C}$, without a high-temperature $\mathrm{CdCl}_{2}$ treatment to promote grain growth and improve PV performance, in order to minimize disruption to the film quality. Results up to $\mathrm{J}_{\mathrm{sc}}=1.4 \mathrm{~mA} / \mathrm{cm} 2, \mathrm{~V}_{\mathrm{oc}}=-0.1 \mathrm{~V}$ and $\mathrm{ff}=28 \%$ were obtained, as shown in Figure 12. Comparison with the dark currents showed that shunting was a major loss mechanism; likely due to physical defects in the film. External quantum efficiency measurements (Figure 13) showed that although the efficiency was low across the wavelength range, the photocurrent generation did extended up to at least $900 \mathrm{~nm}$, thus demonstrating an all-inorganic nanoparticle device with performance extended into the near-IR. At the time of this measurement, the range of our EQE system was limited to a maximum of $900 \mathrm{~nm}$. Improved performance was expected for device receiving a $\mathrm{CdCl}_{2}$ treatment at temperatures elevated to $400 \mathrm{C}$.

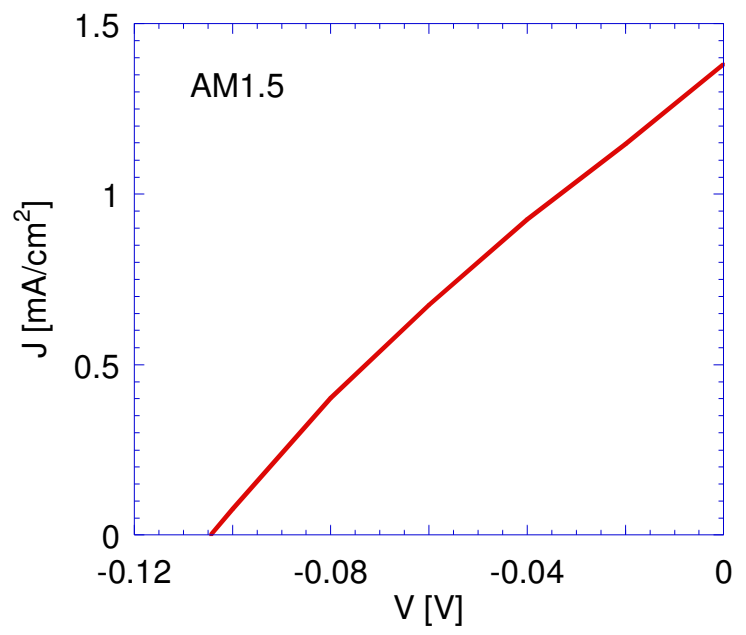

Figure 12: J-V characteristic for an ITO / $\mathrm{Cd}_{\mathrm{x}} \mathrm{Hg}_{1-\mathrm{x}} \mathrm{Te} / \mathrm{CdSe} / \mathrm{Al}$ device processed at only $220 \mathrm{C}$ with no $\mathrm{CdCl}_{2}$ treatment.

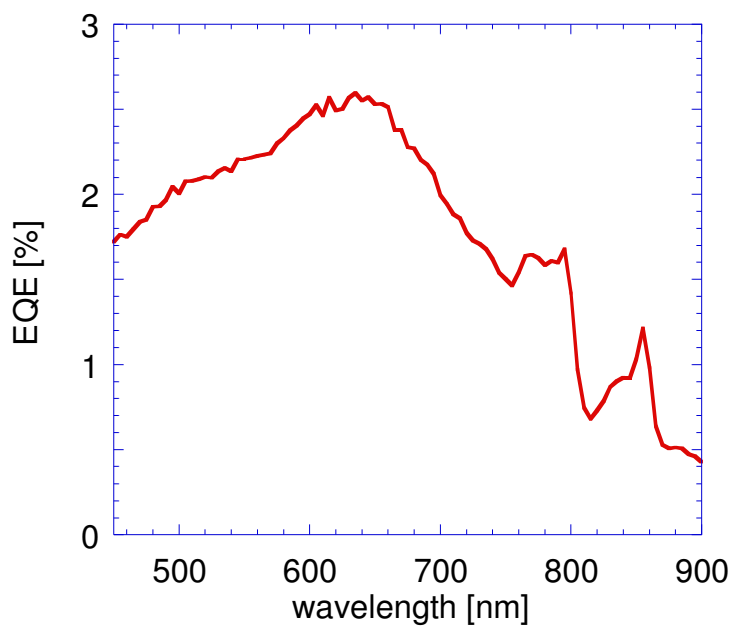

Figure 13: External quantum efficiency vs. wavelength for the ITO / $\mathrm{Cd}_{\mathrm{x}} \mathrm{Hg}_{1-\mathrm{x}} \mathrm{Te} / \mathrm{CdSe} /$ Al device of Figure 12. 
Difficulties were encountered while pursuing further development work on the $\mathrm{Cd}_{\mathrm{x}} \mathrm{Hg}_{1-\mathrm{x}} \mathrm{Te}$ sintered devices, as the $\mathrm{Hg}$ doping level in the $\mathrm{Cd}_{\mathrm{x}} \mathrm{Hg}_{1-\mathrm{x}} \mathrm{Te}$ nanoparticles proved to be challenging to control. One series of experiments indicated a higher percentage of $\mathrm{Hg}$ incorporation than anticipated, as characterized by energy dispersive spectroscopy (EDS), though it should be noted that this measurement technique is spatially limited to a small area $<1 \mu \mathrm{m}$ and may not be representative of the material as a whole. Rather than completely incorporating as an alloy, CdTe and $\mathrm{HgTe}$ might have formed separate phases resulting in an inhomogeneous blend, with some areas more $\mathrm{Hg}$ rich than others. Sintered devices made using this batch of material yielded no photovoltaic response. In response to this, efforts were pursued to more stringently limit the amount of $\mathrm{Hg}$ exchange during synthesis, resulting in particles with $40 \% \mathrm{Hg}$ inclusion $\left(\mathrm{Cd}_{0.6} \mathrm{Hg}_{0.4} \mathrm{Te}\right)$ as characterized by Direct Couple Plasma (DCP). Devices of the type ITO/ $\mathrm{Cd}_{\mathrm{x}} \mathrm{Hg}_{1-\mathrm{x}} \mathrm{Te} / \mathrm{CdSe} / \mathrm{Al}$ were made from this material, with processing including a $400 \mathrm{C} \mathrm{CdCl}_{2}$ sinter treatment. This resulted in functional solar cell devices (Figure 14), but absorption spectra of the sintered films did not show a band-gap decrease compared to CdTe and external quantum efficiency measurements of the devices did not yield photocurrent production above the $850 \mathrm{~nm}$ cut-off value displayed in analogous CdTe devices (Figure 15). We consider three possible theories to explain this scenario: a) alloyed $\mathrm{Cd}_{\mathrm{x}} \mathrm{Hg}_{1-\mathrm{x}}$ Te particles with an even distribution of $\mathrm{Hg}$ throughout the particle volume were made, but for some reason the $\mathrm{Hg}$ migrated outside of the particle during the high temperature $\mathrm{CdCl}_{2}$ sintering process; b) inclusion of $\mathrm{Hg}$ in the $\mathrm{CdTe}$ took the form of a core-shell structure rather than a uniform alloy; c) HgTe particles were formed as separate entities rather than $\mathrm{Hg}$ being incorporated inside the CdTe particles. Each of these theories could result in spatially separated HgTe and CdTe domains. Further material characterization, especially of the sintered nanoparticle films, is required in order to understand what is happening and to correct the deficiency which limited the spectral performance of this material from expanding into the near-IR.
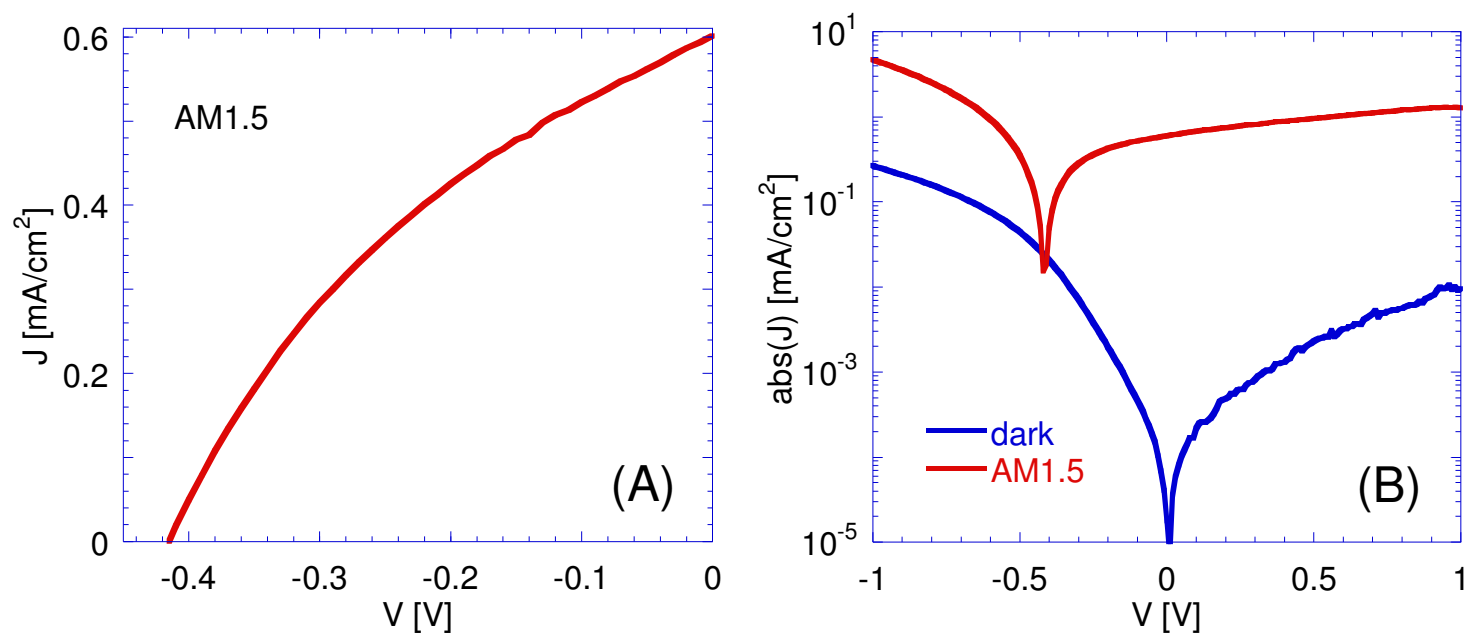

Figure 14: ITO/ $\mathrm{Cd}_{0.6} \mathrm{Hg}_{0.4} \mathrm{Te} / \mathrm{CdSe} / \mathrm{Al}$ device data: (A) under AM1.5 and (B) comparing dark to AM1.5 on a semi-log scale. 


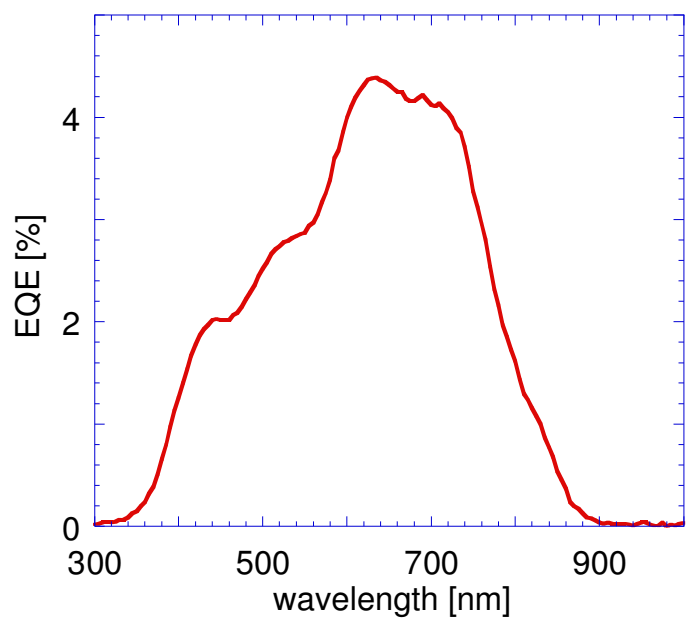

Figure 15: External quantum efficiency spectra for an ITO/ $\mathrm{Cd}_{0.6} \mathrm{Hg}_{0.4} \mathrm{Te} / \mathrm{CdSe} / \mathrm{Al}$ sintered device.

A secondary approach to creating $\mathrm{Cd}_{\mathrm{x}} \mathrm{Hg}_{1-\mathrm{x}} \mathrm{Te}$ films was employed, involving the separate synthesis of both CdTe and $\mathrm{HgTe}$ nanoparticles and subsequently sintering films deposited from a 1:1 blend of the two constituents. Absorption spectra of the resultant films showed a characteristic similar to that of pure CdTe, with no absorption extended past $850 \mathrm{~nm}$.

Our earlier results, though having low device efficiency, demonstrated photocurrent generation past $850 \mathrm{~nm}$ and into the near-IR, showing that $\mathrm{Cd}_{\mathrm{x}} \mathrm{Hg}_{1-\mathrm{x}} \mathrm{Te}$ nanoparticle solar cells are a viable approach for an all-inorganic nanoparticle solar cell functioning in the IR. However, further pursuit to understand the nature of the particles and sintered $\mathrm{Cd}_{\mathrm{x}} \mathrm{Hg}_{1-\mathrm{x}} \mathrm{Te}$ films was cut short by the end of our Phase I award period.

\section{Quantum-confined nanoparticle solar cells}

Our $\mathrm{CdSe} / \mathrm{PbSe}$ sintered nanoparticle device experiments demonstrated that the sintered $\mathrm{PbSe}$ films did not contribute to photocurrent generation, a fact which we attributed in part to the small $0.28 \mathrm{eV}$ band-gap of bulk PbSe. To address this issue, $\mathrm{PbSe}$ and HgTe nanoparticles were investigated as IR-absorbers in non-sintered devices which retained the quantum-confined behavior of the particles and hence provided a comparatively increased band-gap. PbSe particles with a band-gap of $\mathrm{E}_{\mathrm{g}} \sim 0.82 \mathrm{eV}$ and $\mathrm{HgTe}$ particles of $\mathrm{E}_{\mathrm{g}} \sim 0.90 \mathrm{eV}$ were used for these experiments. A variety of Schottkyjunction as well as donor and acceptor heterojunction partner bilayer device designs were construction. Acceptor materials included both sintered $\mathrm{CdSe}$ and $\mathrm{TiO}_{2}$ nanoparticle layers, as well as CdS deposited by chemical bath deposition. Donor materials were represented by sintered CdTe nanorod films. Single layer Schottky-junction devices utilized $\mathrm{Ca}$ and $\mathrm{Al}$ electrodes. Table 1 summarizes the various device structures investigated in this part of the work. Constraints against heating the PbSe and HgTe films (to maintain quantum-confined behavior) and requirements for working in the inert atmosphere glovebox guided device designs such that the bilayer partners (either high 
temperature sintered or chemical bath deposited films) had to be deposited prior to $\mathrm{PbSe}$ or HgTe layers.

\begin{tabular}{|c|c|c|c|}
\hline & bilayer partner & $\mathrm{PbSe}$ & HgTe \\
\hline \multirow{6}{*}{$\begin{array}{l}\text { Bilayer } \\
\text { devices }\end{array}$} & \multirow{2}{*}{ CdSe } & ITO / CdSe / PbSe / Au & ITO / CdSe / HgTe / Au \\
\hline & & ITO / CdSe / PbSe / Al & \\
\hline & \multirow{2}{*}{ CdS } & $\mathrm{ITO} / \mathrm{CdS} / \mathrm{PbSe} / \mathrm{Au}$ & ITO / CdS / HgTe / Au \\
\hline & & ITO / CdS / PbSe / Al & \\
\hline & CdTe & ITO / CdTe / PbSe / Al & ITO / CdTe / HgTe / Al \\
\hline & $\mathrm{TiO}_{2}$ & & ITO / $\mathrm{TiO}_{2} / \mathrm{HgTe} / \mathrm{Au}$ \\
\hline \multirow{2}{*}{$\begin{array}{c}\text { Schottky } \\
\text { devices }\end{array}$} & & $\mathrm{ITO} / \mathrm{PbSe} / \mathrm{Ca} / \mathrm{Al}$ & \\
\hline & & ITO / PbSe / Al & \\
\hline
\end{tabular}

Table 1: Device structures investigated for PbSe and HgTe quantum-confined, nonsintered nanoparticle devices.

$\mathrm{PbSe}$ and $\mathrm{HgTe}$ nanoparticle layers were deposited via a layer-by-layer dipcoating process. An in-film exchange of the native ligand on the nanoparticle for a less soluble ligand allowed for multiple coating depositions without removing the prior nanoparticle layers. The exchange ligand has the added benefit of promoting improved charge transport, as it is smaller than the original more bulky ligands and leads to short inter-particle distance, and hence better conductivity, while retaining the quantumconfined characteristics of the material.

Various in-film ligand exchange treatments have been discussed in the literature, including hydrazine, pyridine, methlamine and ethanedithiol (EDT). For our work, we used a 0.1M EDT solution in acetonitrile (ACN). All PbSe and $\mathrm{HgTe}$ film work, from fabrication through device testing, was performed under inert atmosphere to avoid oxidation of the nanoparticle surface. Substrates were dipped in a dilute $5 \mathrm{mg} / \mathrm{ml}$ nanoparticle solution, where the solvent was a chloroform:hexane blend. The substrates were removed from solution at a rate of 0.1-0.2 inches/second, leaving behind a monolayer of nanoparticles. After air drying, the film was dipped in the EDT solution for 3-5 seconds to exchange EDT for the native ligand, removed and then rinsed with ACN and blown dry. Repetition of this process anywhere from 20-40 times yielded shiny films ranging from 100-200nm in thickness. Characterization of the surface topology with AFM showed smooth films with a surface roughness on the order of $R_{a}=1 \mathrm{~nm}$ for a typical PbSe film (Figure 16A) . Cross section SEM (Figure 16B) confirmed the films were continuous and dense. Shiny films were also obtained for HgTe, though the surface roughness increased slightly to $\mathrm{R}_{\mathrm{a}}=7 \mathrm{~nm}$. 

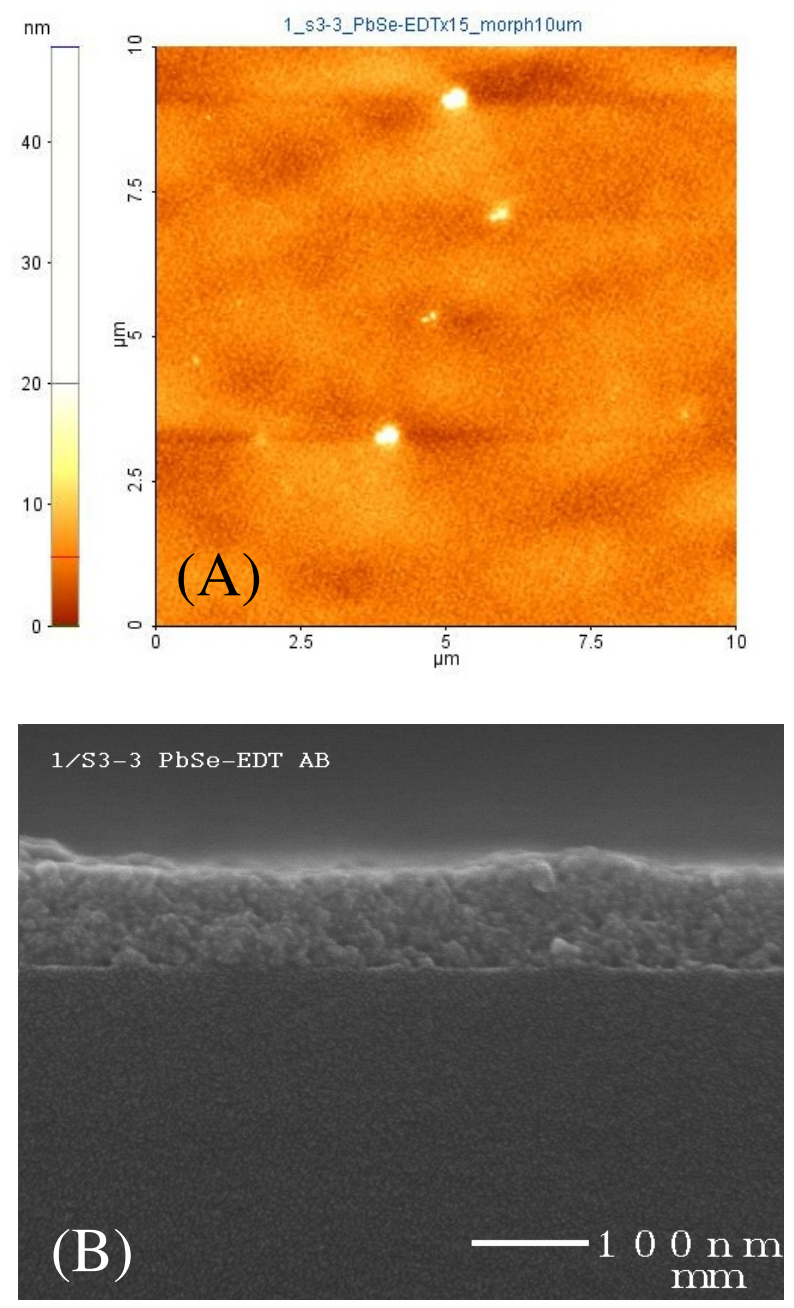

Figure 16: (A) AFM surface topology of a layer-by-layer deposited PbSe; (B) crosssectional SEM of the same film.

CdTe and CdSe films were spin-cast from nanoparticle solutions and sintered at $400 \mathrm{C}$ in either inert (CdTe) or ambient (CdSe) atmosphere for 15 minutes. CdS was deposited by chemical bath deposition and receive no further treatment prior to the absorber layer deposition. Electrodes were thermally evaporated in a chamber inside the glovebox so that the PbSe and HgTe films were not exposed to oxygen.

\section{PbSe quantum-confined nanoparticle devices}

The PbSe layers did not demonstrate photocurrent generation in any of the bilayer or Schottky-junction devices explored during this award. In the case of the Schottky and the $\mathrm{CdTe} / \mathrm{PbSe}$ structures, devices did not produce any photocurrent or photovoltage. The $\mathrm{CdSe} / \mathrm{PbSe}$ structures produced working solar cell devices, but as illustrated in Figure 17B for the $\mathrm{CdSe} / \mathrm{PbSe}$, a comparison of the EQE with the absorption spectra of the individual films shows that photocurrent was produced in the CdSe with no contribution 
from the $\mathrm{PbSe}$. The photocurrent spectral range matches that of $\mathrm{CdSe}$ absorption, showing no photocurrent generation above the CdSe 750nm band-edge.

Investigations completed after the end of this grant solved the mystery of why the quantum-confined $\mathrm{PbSe}$ was not photoactive. The band-gap requirements for $\mathrm{PbSe}$ to contribute photocurrent are apparently even more restrictive than we initially assumed. Decreasing the particle size and subsequently increasing the bandgap to a value of $1.0 \mathrm{eV}$ yielded photocurrent producing PbSe thin film devices.
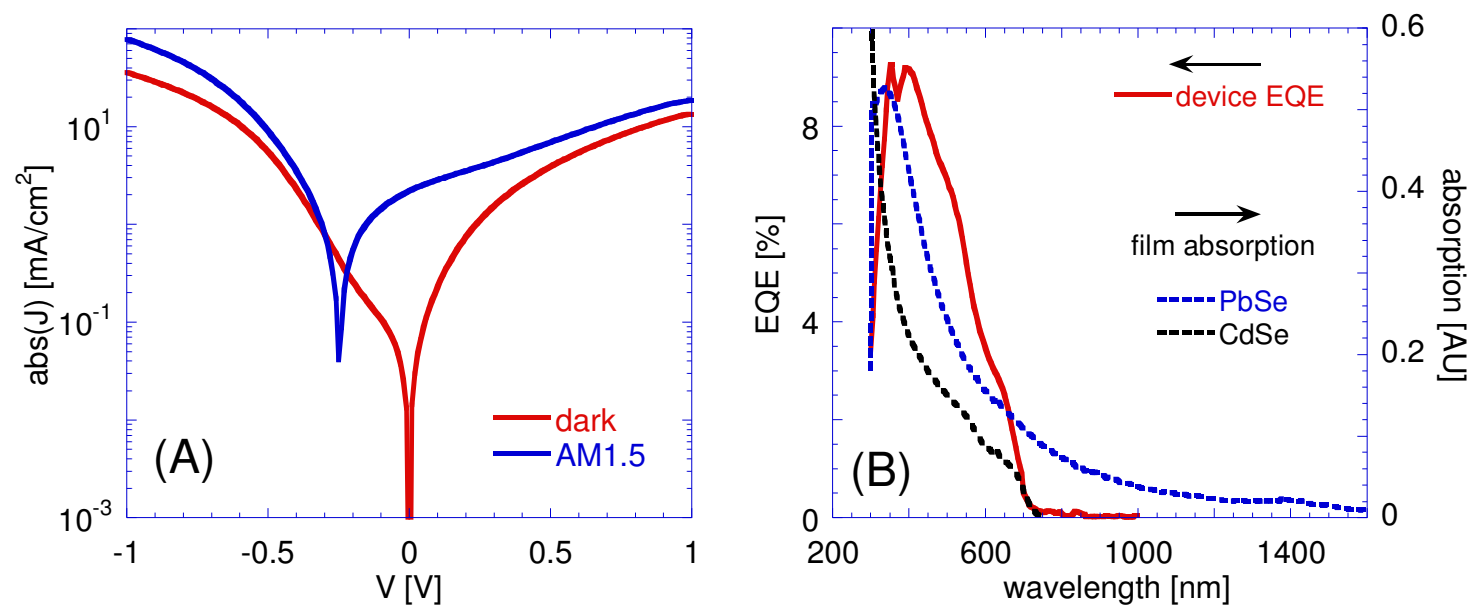

Figure 17: (A) J-V results for an ITO/CdSe/PbSe/Al device producing $\mathrm{J}_{\mathrm{sc}}=2.2 \mathrm{~mA} / \mathrm{cm}_{2}$, $\mathrm{V}_{\mathrm{oc}}=-0.25 \mathrm{~V}$ and $\mathrm{ff}=29 \%$; (B) $\mathrm{EQE}$ for an $\mathrm{ITO} / \mathrm{CdSe} / \mathrm{PbSe} / \mathrm{Au}$ device, with the absorption spectra of $\mathrm{CdSe}$ and $\mathrm{PbSe}$ films plotted for comparison.

\section{HgTe quantum-confined nanoparticle devices}

The HgTe bilayer devices did produce photocurrent created in the HgTe layer when paired with $\mathrm{CdS}, \mathrm{CdSe}$ or $\mathrm{TiO}_{2}$. The ITO / CdS / HgTe / Au device shown in Figure $18 \mathrm{~A}$ achieved $\mathrm{J}_{\mathrm{sc}}=11 \mathrm{~mA} / \mathrm{cm} 2, \mathrm{~V}_{\mathrm{oc}}=-0.17 \mathrm{~V}$ and $\mathrm{ff}=23 \%$. The $\mathrm{HgTe}$ contribution to the photocurrent was most evident in the $\mathrm{CdS} / \mathrm{HgTe}$ and $\mathrm{TiO}_{2} / \mathrm{HgTe}$ devices, where the absorption range of the partner material was either limited to lower wavelengths (CdS) or the material was mostly transparent in the visible range $\left(\mathrm{TiO}_{2}\right)$. Figure $18 \mathrm{~B}$ plots the $\mathrm{CdS}$ / HgTe device EQE alongside the CdS and HgTe film absorption. The EQE magnitude is highest below 520nm, but it does extend up to $800 \mathrm{~nm}$. As can be seen from the bandedge of $\mathrm{CdS}$, photocurrent produced above 520nm must be originating from the $\mathrm{HgTe}$ absorption. However, though HgTe absorption extends past $1500 \mathrm{~nm}$, the absorption strength is maximized in the visible range below 600nm. As a result, the $\mathrm{HgTe}$ devices produced insufficient photocurrent in the near-IR to meet our objectives. From this experiment, we learned an important criterion for IR-solar cell material selection. Though a variety of nanoparticles exhibit absorption throughout the near-IR, and are often touted as attractive IR-absorbers with adjustable bandgaps, such characteristics are not a sufficient condition for the production of solar cells with decent efficiency in that region of the spectrum. For planar device designs, it is also required that the absorption coefficient has a high value in the region of interest in order to absorb enough light to produce a photocurrent sufficient for high performance. While some of this issue can be addressed by increasing the thickness of the absorber layer, this can only be adjusted to a 
certain point before charge transport losses begin to have a negative impact on performance.
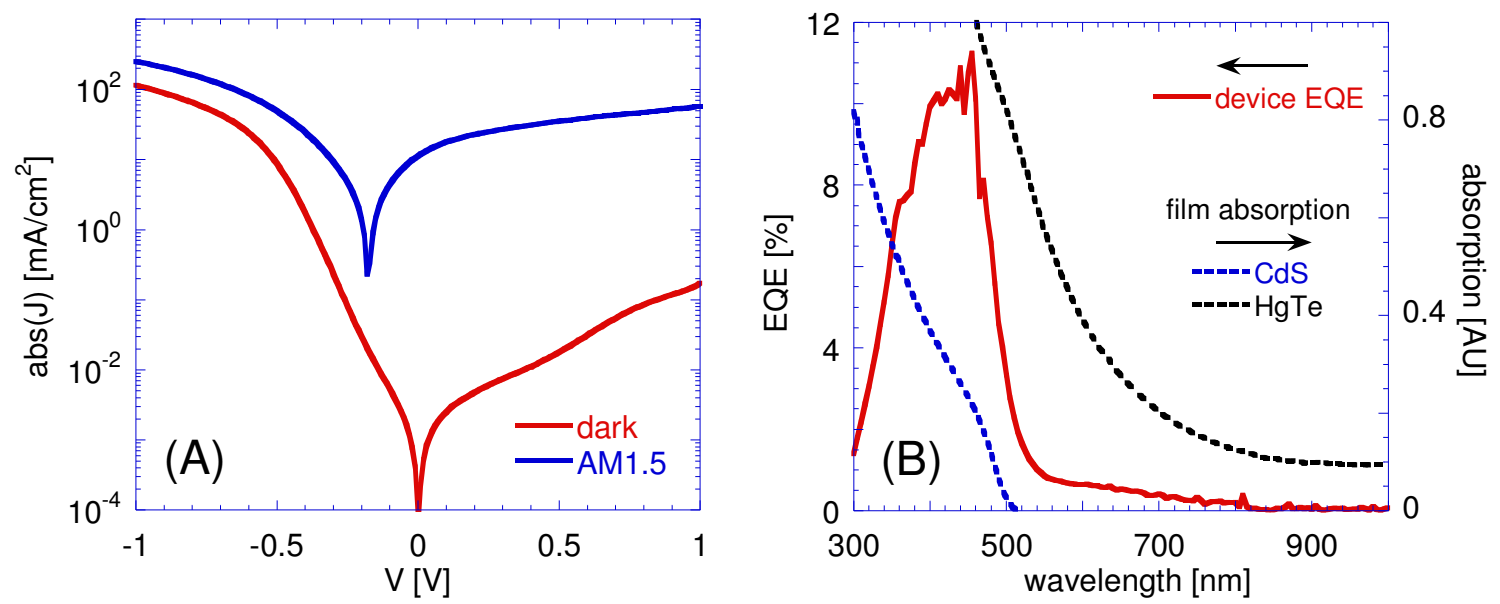

Figure 18: ITO / CdS / HgTe / Au device results: (A) J-V curves in the dark and under AM1.5; (B) EQE with the absorption spectra of CdS and HgTe films plotted for comparison.

\section{CdTe / CdSe sintered nanoparticle devices}

The CdTe / CdSe device system was used as a vehicle to expand our general understanding of all-inorganic nanoparticle solar cell physics. Additionally, it was anticipated that the knowledge gained from studying this system would be directly applicable to understanding and improving the $\mathrm{Cd}_{\mathrm{x}} \mathrm{Hg}_{1-\mathrm{x}} \mathrm{Te} / \mathrm{CdSe}$ devices discussed above. We fabricated ITO/CdTe/CdSe/Al solar cells with a short-circuit current of 18.7 $\mathrm{mA} / \mathrm{cm}^{2}$, an open-circuit voltage of $0.404 \mathrm{~V}$, and a fill factor of $34 \%$, yielding a power efficiency of $2.6 \%$. This result exceeds the efficiency reported by Gur et al. for Al electrodes, without the need for an additional atomic layer deposited $\mathrm{Al}_{2} \mathrm{O}_{3}$ layer. The $\mathrm{CdTe} / \mathrm{CdSe}$ devices were shown to contribute to the quantum efficiency out-to to $900 \mathrm{~nm}$. We studied a wider variety of electrodes and demonstrated that the electrode selection, with the exception of PEDOT-PSS, did not substantially affect the device performance. We also studied the sintering conditions and showed the devices are highly sensitive to sintering temperature, indicating that the optimization of the sintering conditions, as well as interface layers, will be the best route to significantly improve device efficiency. Finally, we measured the temperature dependence of an all-inorganic nanoparticle solar cell for the first time, and demonstrated that $\mathrm{J}_{\mathrm{sc}}$ increases with increasing temperature while $\mathrm{V}_{\mathrm{oc}}$ decrease with increasing temperature. This behavior is reminiscent of polymer-nanoparticle donor-acceptor heterojunctions or Schottky devices, rather than $\mathrm{p}$-n junction devices. A paper on these results is currently being written. 
The fabrication of $\mathrm{CdTe} / \mathrm{CdSe}$ devices was similar to the process used to fabricate the $\mathrm{CdTe} / \mathrm{PbSe}$ solar cells, with nanorods replacing the nanoparticle form for CdSe. Devices were fabricated by spin coating $\mathrm{CdTe}$ and then CdSe on a patterned ITO substrate and annealing at 215-220C between layers. Prior to electrode deposition, the device was treated with $\mathrm{CdCl}_{2}$ in methanol and then sintered in air at $400 \mathrm{C}$ in a standard single-zone tube furnace. A variety of electrodes, including $\mathrm{Ca}, \mathrm{LiF}, \mathrm{Al}$, and $\mathrm{Au}$ were

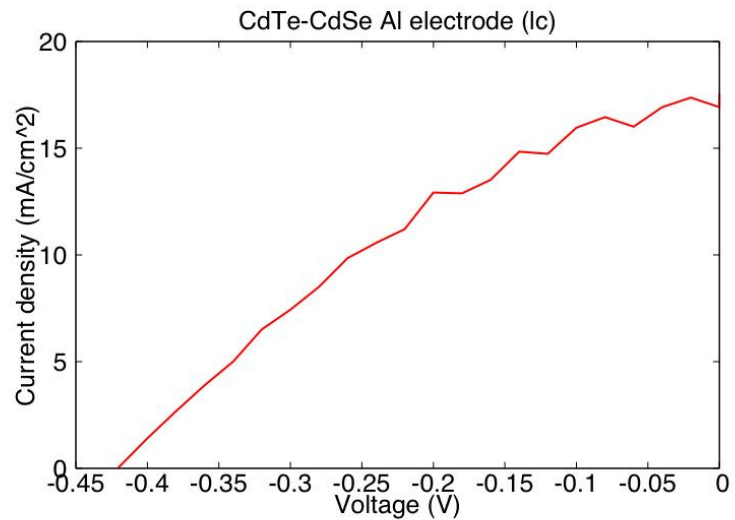

Figure 19: ITO/CdTe/CdSe/Al solar cell with a power efficiency $>2.5 \%$. deposited by thermal evaporation while PEDOT-PPS was deposited by spin casting. A typical IV-curve for one of the better devices is shown in Figure 19. While $\mathrm{J}_{\mathrm{sc}}$ above 15 $\mathrm{mA} / \mathrm{cm}^{2}$ was observed on several different batch runs at both UCSC and Solexant, currents of $\sim 3$ to $5 \mathrm{~mA} / \mathrm{cm}^{2}$ were more typical. The difference in the currents was related to differences in the nanoparticle solutions, particularly with aging, as well as the sintering conditions. What synthesis conditions result in the best device performance is still under investigation.

In Figure 20a, the performance for an unsintered device is shown, revealing a large reduction in $\mathrm{J}_{\mathrm{sc}}$, and a significant variation in $\mathrm{J}_{\mathrm{sc}}$ was also observed with changes in the annealing temperatures as small as 10 degree (Figure 20b). Given that the single zone furnace we used has a variation of over 10 degrees in its temperature uniformity, more control over the temperature, as afforded by a three zone furnace, is required for device optimization and reproducibility.
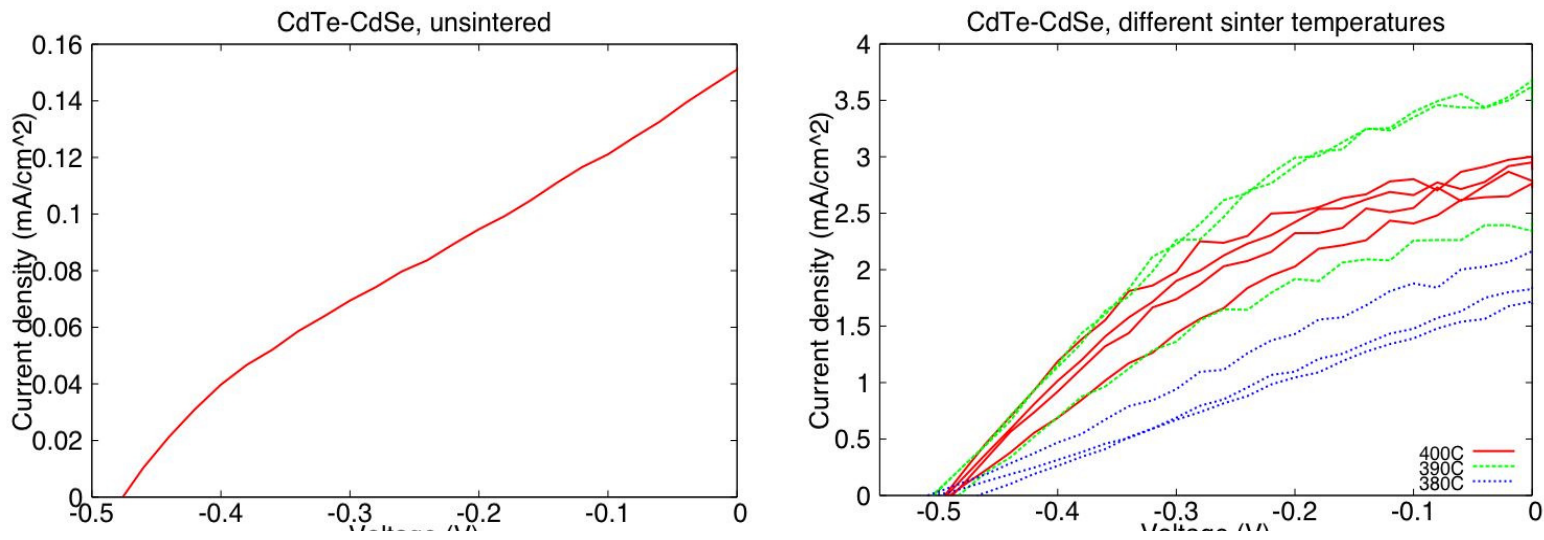

Figure 20: Typical performance of an ITO/CdTe/CdSe/Al solar cell that has been (a) unsintered, and (b) sintered at different temperatures, 380 to $400 \mathrm{C}$.

We tested the effect of several different electrodes, including Au, PEDOT/Au, Al, $\mathrm{Ca}$, and $\mathrm{LiF} / \mathrm{Al}$. In general, the $\mathrm{CdTe} / \mathrm{CdSe}$ devices are insensitive to choice of electrodes. In Figure 21, the effect of $\mathrm{Al}$ and $\mathrm{Au}$ electrodes on device performance is shown for $\mathrm{CdTe} / \mathrm{CdSe}$ and for $\mathrm{CdS} / \mathrm{CdTe}$ for comparison purposes. The only substantial 
electrode dependence for $\mathrm{CdTe} / \mathrm{CdSe}$ devices was observed when PEDOT-PPS was spun-cast between the $\mathrm{CdSe}$ and $\mathrm{Au}$ interface, resulting in very low $\mathrm{V}_{\mathrm{oc}}$. In contrast, $\mathrm{CdS}$ (deposited by chemical bath deposition) and CdTe nanoparticle devices showed strong electrode dependence, with the largest $\mathrm{V}_{\mathrm{oc}}$ occurring for PEDOT-PSS electrodes. This indicated that these devices operate by fundamentally different mechanisms. We further note that the typical device performance is very similar for the $\mathrm{CdS} / \mathrm{CdTe}$ vs. $\mathrm{CdSe} / \mathrm{CdTe}$ devices, further suggesting that the CdTe material and the sintering conditions may be the limiting factor controlling device performance for both systems.

Approaches to further improve device performance are suggested by cross-sectional SEM (taken at the Molecular Foundry in Berkeley). In Figure 22, typical SEMs are shown for a sintered $\mathrm{CdTe} / \mathrm{CdSe}$ bilayer on a silicon substrate. The CdTe layer forms grains on the order of $10 \mathrm{~nm}$ in diameter while the thin CdSe layer forms a more columnar structure oriented normal to the substrate. Large voids are frequently observed, particularly at the $\mathrm{CdSe} / \mathrm{CdTe}$ interface, indicating that improvement to this interface will be needed for better device performance. In addition, more crystallinity of the CdTe layer will be needed to increase mobility and ultimately $\mathbf{J}_{\mathrm{sc}}$ and the fill factor.
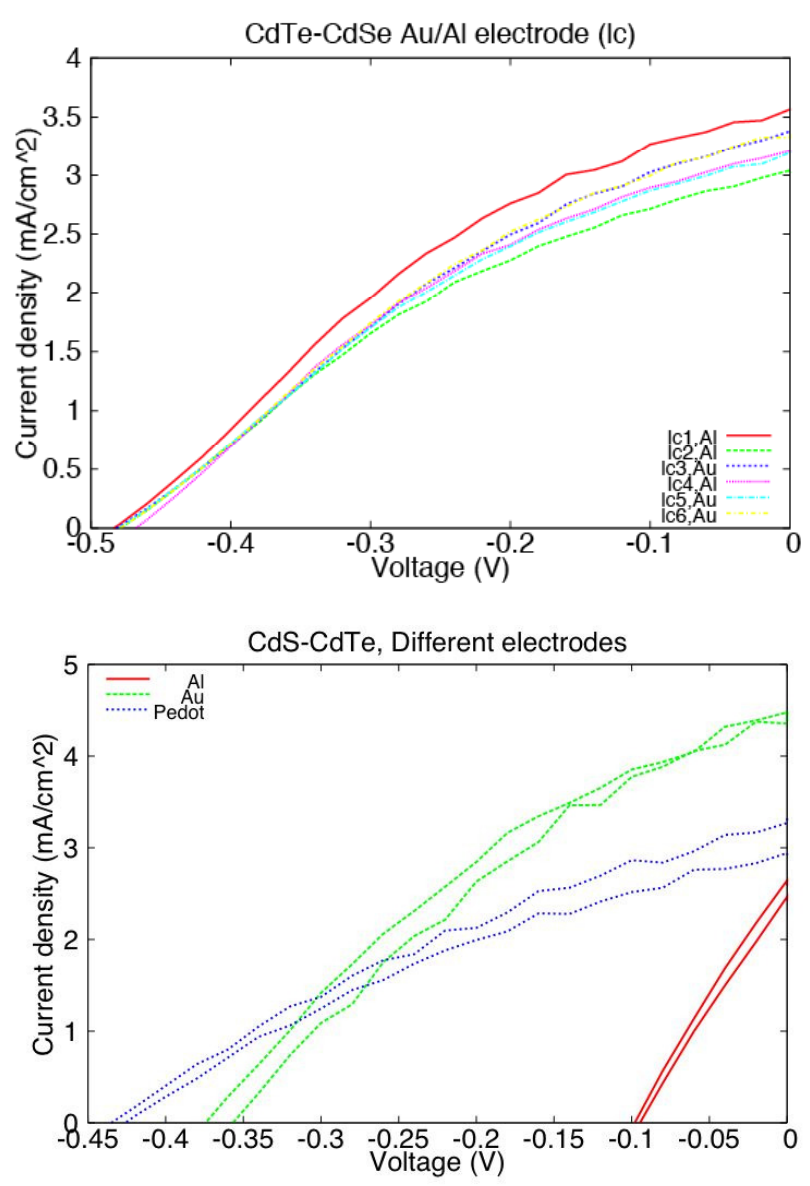

Figure 21: The effect of device performance on electrodes for (a) CdTe/CdSe and (b) CdS/CdTe. 


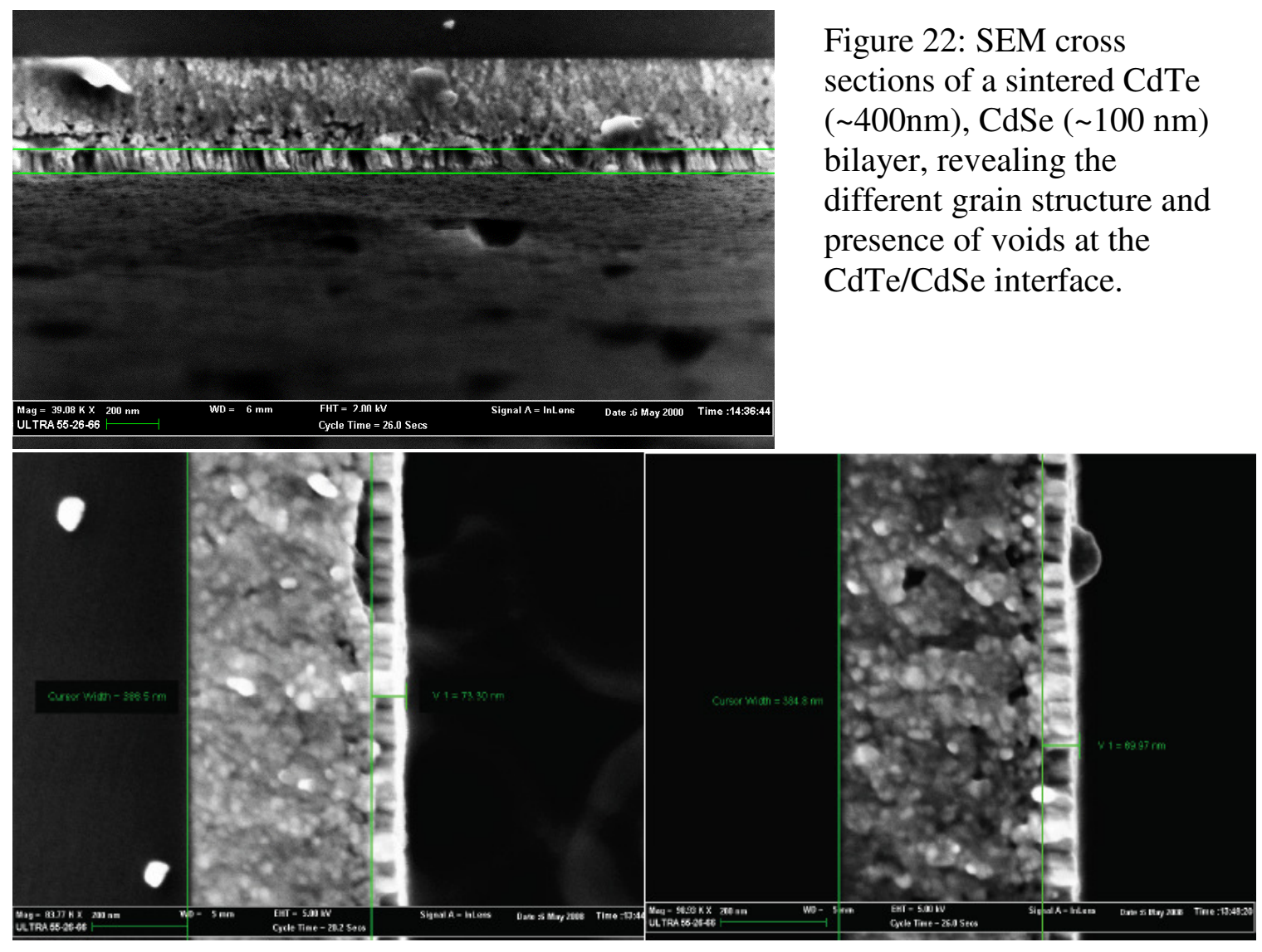

The temperature dependence of a typical CdTe/CdSe device is shown in Figure 23. Remarkably, a very strong $T$-dependence for both $V_{\text {oc }}$ and $J_{s c}$ is observed. The $J_{s c}$ drops by a factor of 4 and the $\mathrm{V}_{\text {oc }}$ more than doubles between $350 \mathrm{~K}$ and $100 \mathrm{~K}$. The $\mathrm{V}_{\mathrm{oc}}$ reaches $0.85 \mathrm{~V}$ at $100 \mathrm{~K}$, suggesting that substantial improvements can be made.

Surprisingly, the temperature dependence of the CdSe:P3HT blends is similar, although not as strong, as the all inorganic $\mathrm{CdTe} / \mathrm{CdSe}$ devices. This result could indicate that transport in the CdTe is dominated by hopping, as is the case for the P3HT polymer. Alternatively, the decrease in $\mathrm{J}_{\mathrm{sc}}$ with decreasing temperature may be indicative of a Schottky barrier play an important role in the device performance. 


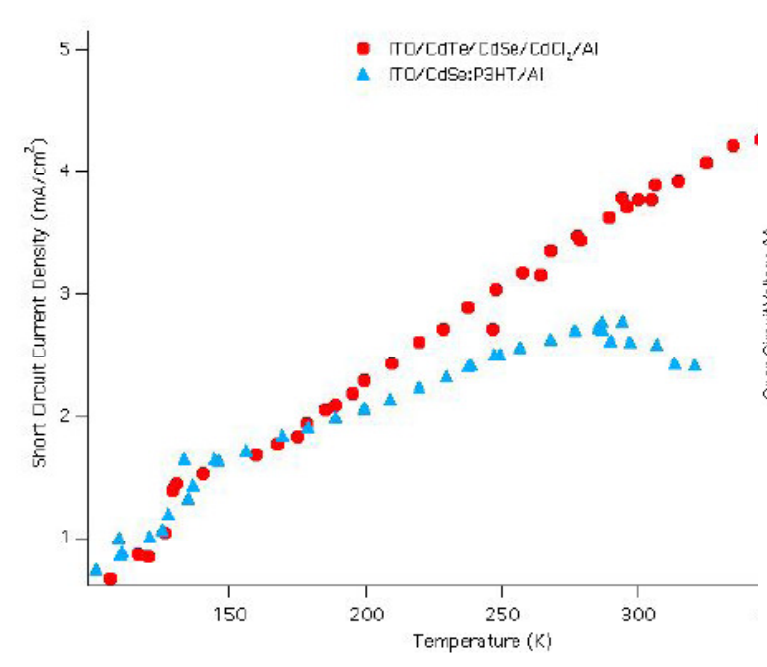

(a) Short Circuit Current

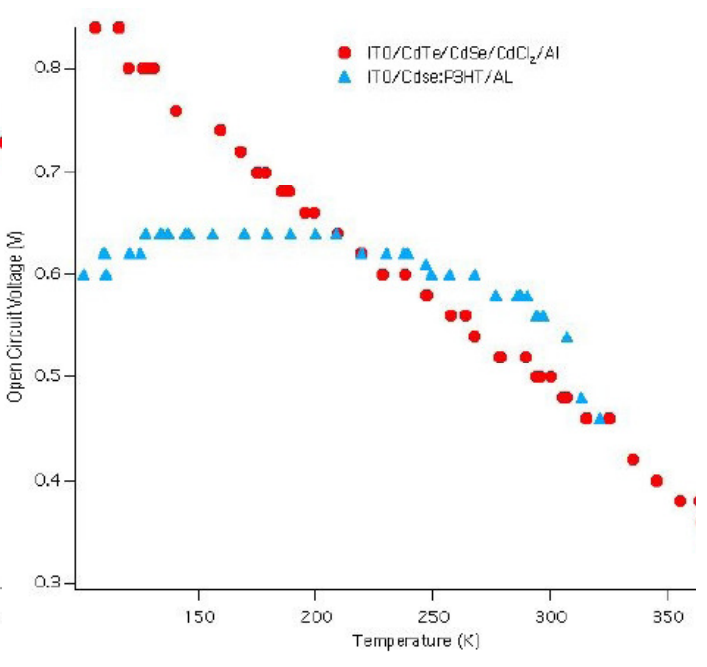

(b) Open Circuit Voltage

Figure 23: The temperature dependence for sintered ITO/CdT/CdSe/Al and ITO/CdSe:P3HT blend for comparison, showing (a) $\mathrm{J}_{\mathrm{sc}}$ and (b) $\mathrm{V}_{\mathrm{oc}}$

Changes in the absorption before and after sintering (Figure $24 b)$ reveal a shift towards bulk behavior due to loss of quantum confinement of the nanoparticles. The onset of the absorption (and quantum efficiency) is on the order of $840 \mathrm{~nm}$, which is near the $1.5 \mathrm{eV}$ bulk bandgap for CdTe. The fall off in absorption and quantum efficiency at shorter wavelengths is due to absorption by the substrate (quartz and glass, respectively). Curiously, the external quantum efficiency, shown in Figure 24b, appears to start at close to $\sim 900 \mathrm{~nm}$ which is below the bandgap of pure CdTe. This suggests that interface doping or defect states in the gap are contributing to the short circuit current. Overall, a peak external quantum efficiency near $50 \%$ is observed for the better devices. An appreciable quantum efficiency of up to $30 \%$ is still observed in the IR region between 700 and $900 \mathrm{~nm}$; however this
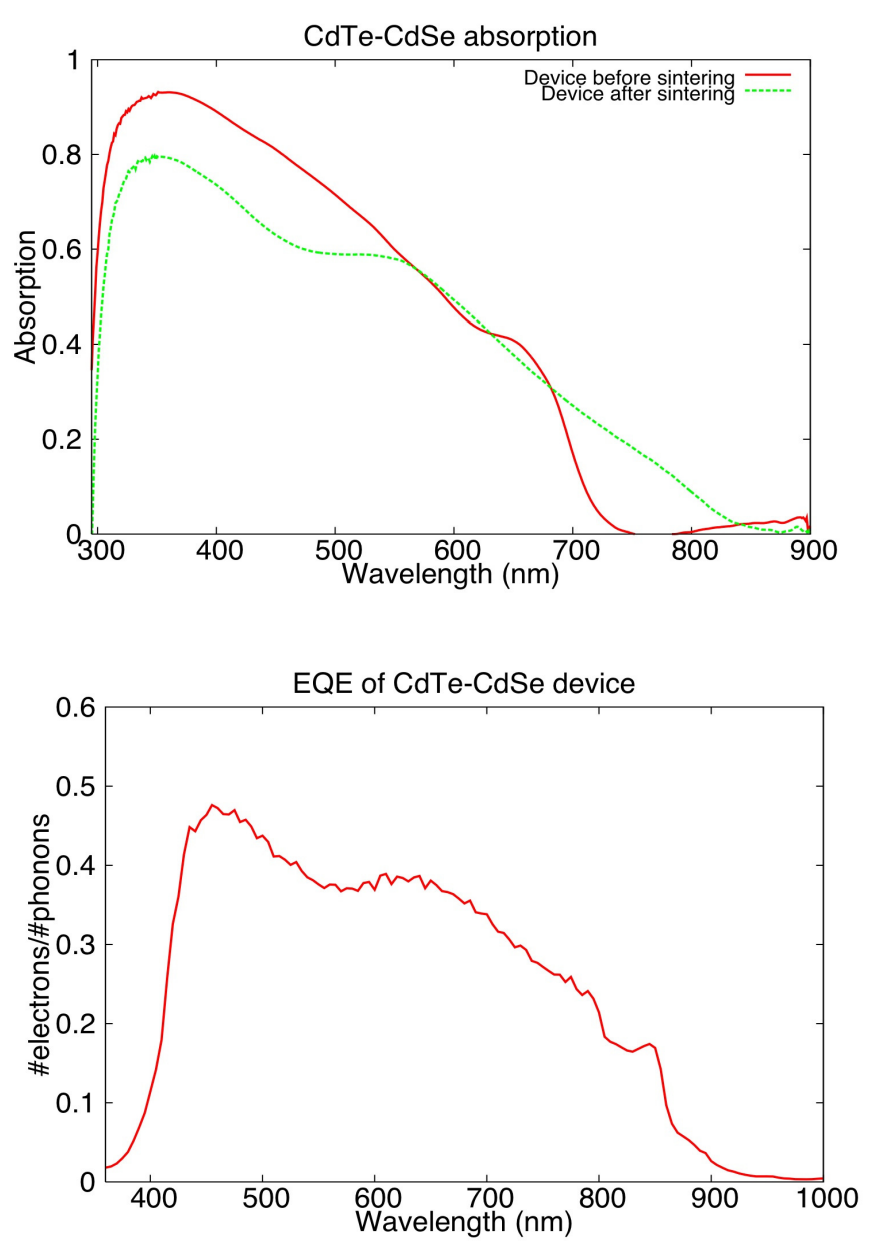

Figure 24: Top: absorption of a sintered and nonsintered CdTe/CdSe. Bottom: External quantum efficiency of a sintered $\mathrm{CdTe} / \mathrm{CdSe}$ device. 
still results in a power efficiency less than $1 \%$ in the near-IR for the best-device.

\section{Conclusions}

Though the performance of the devices generated under this grant were less than originally predicted at the outset of the study, we believe that the work completed under this award offers strong insight into viable avenues of research for this area in the future.

We presented proof-of-concept results demonstrating that non-sintered $\mathrm{Cd}_{\mathrm{x}} \mathrm{Hg}_{1-}$ ${ }_{x}$ Te nanoparticle devices represent one such pathway towards achieving solar cell performance in the near-IR wavelength regime. Further work to characterize the material properties of the sintered films is required in order to proceed with this research, but once that issue is solved, the $\mathrm{Cd}_{\mathrm{x}} \mathrm{Hg}_{1-\mathrm{x}}$ Te system is very promising.

Other research completed over the course of this award has given greater insight into the criteria necessary to produce a functional quantum-confined nanoparticle-based solar cell with efficient performance in the near-IR. Material band-gap was demonstrated to be a crucial factor for PbSe devices, where changing the band-gap from 0.8 to $1.0 \mathrm{eV}$ made the difference between non-functional and functional $\mathrm{PbSe}$ films. In the case of $\mathrm{Hg}$ devices, the absorption strength of the material as a function of wavelength was shown to be just as important as the absorption range in general. It is not sufficient to select a material which absorbs in the near-IR - it must absorb strongly in that range.

While we did not observe a near-IR response for the $\mathrm{CdSe} / \mathrm{PbSe}$ devices, our work revealed the important role that buffer layers play in reducing shorting and improving device performance for all inorganic nanoparticle solar cells. Further control over the interfaces using buffer layers will likely play as valuable a role for nanoparticle solar cells as it does for thin film solar cells.

Finally, our ability to further improve on $\mathrm{CdTe} / \mathrm{CdSe}$ nanoparticle solar cells by eliminating the need of an $\mathrm{ALD} \mathrm{Al}_{2} \mathrm{O}_{3}$ layer or $\mathrm{Ca}$ electrode and to further elucidate the mechanisms that will be responsible to improve device performance will be extremely valuable for producing a commercially viable nanoparticle solar cell. Although our goal was to study $\mathrm{CdTe} / \mathrm{CdSe}$ as a model system to understand nanoparticle solar cells, and not to obtain a large IR response, we still observed one of the highest near-IR quantum efficiencies every observed in a nanoparticle-based solar cells. This promising result suggests that just minor doping of the CdTe layer will be sufficient to harness a substantial fraction of the near-IR spectrum.

All-inorganic nanoparticle-based solar cells are a very new field, but they offer numerous advantages including ease of tuning the material properties via control of material synthesis, the economical fabrication of solution-processing deposition and likely a system less vulnerable to degradation than their counterpart solution-processed organic photovoltaic materials. 